Article

\title{
Revisiting the Dynamic Linkages of Treasury Bond Yields for the BRICS: A Forecasting Analysis
}

\author{
Stelios Bekiros ${ }^{1,2, *}$ and Christos Avdoulas ${ }^{2,3}$ \\ 1 Department of Economics, European University Institute (EUI), I-50014 Florence, Italy \\ 2 Athens University of Economics and Business, (AUEB), 10434 Athens, Greece; avdoulasx@interamerican.gr \\ 3 Interamerican Research Center (IRC), INTERAMERICAN part of ACHMEA, 11782 Athens, Greece \\ * Correspondence: stelios.bekiros@eui.eu; Tel.: +39-05-5468-5925; Fax: +39-05-5468-5902
}

Received: 1 April 2020; Accepted: 12 May 2020; Published: 16 May 2020

\begin{abstract}
We examined the dynamic linkages among money market interest rates in the so-called "BRICS" countries (Brazil, Russia, India, China, and South Africa) by using weekly data of the overnight, one-, three-, and six- months, as well as of one year, Treasury bills rates covering the period from January 2005 to August 2019. A long-run relationship among interest rates was established by employing the Vector Error Correction modeling (VECM), which revealed the validation of the Expectation Hypothesis Theory (EH) of the term structure of interest rates, taking into account long-run deviations from equilibrium and inherent nonlinearities. We unveiled short-run dynamic adjustments for the term structure of the BRICS, subject to regime switches. We then used Markov Switching Vector Error Correction models (MS-VECM) to forecast them dynamically during an out-of-sample period of May 2016 through August 2019. The MSIH-VECM forecasts were found to be superior to the VECM approaches. The novelty of our paper is mainly due to the exploration of the possibility of parameter instability as a crucial factor, which might explain the rejection of the restricted version of the cointegration space, and on the dynamic out-of-sample forecasts of the term structure over a more recent time span in order to assess further the usefulness of our nonlinear MS-VECM characterization of the term structure, capturing the effects of the global and domestic financial crisis.
\end{abstract}

Keywords: BRICS; term structure; cointegration dynamics; Markov-switching; forecasting

\section{Introduction}

Forecasting money market interest rates is always a crucial issue for economists and policy makers. Additionally, the term structure of interest rates is of utmost importance for the transmission of monetary policy. The expectations hypothesis (henceforth $\mathrm{EH}$ ) represents the most influential theoretical explanation for term structure relations indicating that the long-term rate is determined purely by current and future expected short-term rates. Therefore, "Interest rate dynamics" have implications for various market participants and understanding their interrelations becomes essential not only for economists and monetary policy makers but also for risk management practitioners. In addition, understanding the $\mathrm{EH}$ of the term structure of interest rates is a core issue for Treasury managers in order to perform active sovereign debt management, since the maturity structure of public debt affects the government budget. Recently, domestic term structure is influenced mostly by external term structures and monetary policies due to the liberalization of international financial markets Beechey et al. [1], and this may be the case in BRICS. Thus, this paper tries to investigate the expectations hypothesis of the term structure of interest rates in BRICS countries.

The BRICS countries label refers to a select group of five large, developing countries (Brazil, Russia, India, China, and South Africa). The five BRICS countries are distinguished from a host of 
other promising emerging markets by their demographic and economic potential to rank among the world's largest and most influential economies in the 21st century (and by having a reasonable chance of realizing that potential). Together, the five BRICS countries comprise more than 2.8 billion people or $42.6 \%$ of the global population and nearly half of the world's foreign exchange reserves. In addition, BRICS countries have seen 10 years of rapid expansion in trade and economic growth. They currently account for nearly a quarter of the world economy and contributed more than half of global economic growth in 2016. Furthermore, BRICS have set up a development bank which is now known as the New Development Bank (NDB) where the different countries intend to address the group's economic challenges with combined resources. Countries in the BRICS group have either undergone or are undergoing structural changes in their monetary policy frameworks [2]. The way in which interest rates in the different countries correlate is, to a certain extent, affected by structural changes.

The purpose of this study was to be the first of its kind to identify whether the $\mathrm{EH}$ of the term structure of interest rates holds in BRICS countries, to explore the possibility of parameter instability as a crucial factor which might explain the rejection of the restricted version of the cointegration space, and to assess further the usefulness of nonlinear characterization of the term structure of interest rates, over a more recent time span covering the period between January 2005 and August 2019 covering the global financial crisis started in 2008, the Brazil political crisis in 2014-2016, the China stock market bubble in 2015, and the Russian oil recession crisis in 2014.

Our study was motivated by previous works reported in the literature on the presence of regime shifts (e.g., Reference [3,4]), as well as by the relative forecasting success of the nonlinear MS-VECM models of the term structure of interest rates (e.g., Reference [5]). The research was also prompted by the concept that there are economic reasons for believing that allowing for regime shifts and asymmetries can provide potentially important insights into the behavior of the entire yield curve. Business cycle expansions and contractions may have important effects on expectations of inflation, monetary policy, and nominal interest rates, so that regime shifts may generate significant impacts both on the short-term interest rate and on the entire term structure.

Following Reference [5], we analyze the term structure dynamics of the interest rates of BRICS countries under five different maturities, by utilizing data of weekly frequency between 2005 and 2019 . There are several important findings which stem from our exhaustive econometric estimation approach. Firstly, we robustly estimate the rank of the cointegration space for the system of the five rates. Results show that there are exactly four cointegrating relationships between the five rates for India and South Africa and three cointegrating vectors for Brazil, China and Russia. Secondly, we impose independent linear and homogeneous restrictions which are implied by the fulfilment of the EH. We impose various sets of restrictions implemented upon a sub-section of the estimated cointegration space. In this partially identified cointegration space, we are able to show that part of the restrictions from the EH cannot be rejected. More specifically, for India and South Africa, the estimated VECM model identified a one-to-one long-run relationship between (i) overnight and 1-month Treasury bill, (ii) overnight and 3-months bill, (iii) overnight and 6-months Treasury bill and (vi) overnight and 1-year bill whilst for the Brazil, China, and Russia the VECM identified a one-to-one long-run relationship between the (i) overnight and 1-month Treasury bill, (ii) overnight and 3-months bill, and the (iii) overnight and 6-months Treasury bill. Thirdly, we explore the possibility of parameter instability as a crucial factor which might explain the rejection of the restricted version of the cointegration space; to that end, we apply the recursive tests of Hansen and Johansen [6,7], which show that the dimension of the cointegration space is sample independent and the estimated coefficients exhibit instabilities in recursive estimations during Global financial crisis started in 2008. Fourthly, we show that, while a long run equilibrium relationship between the five different maturities can be established, consistently with the expectations theory of the term structure, the linear vector error correction models are rejected when tested against regime-switching vector error correction models. Fifthly, we employ a Markov switching vector error correction approach to analyze the dynamic relationship between interest rates for the different maturities of each country, implementing the robust estimation techniques introduced 
by [8]. Eventually, we are able to fully identify and characterize the dynamic relationships between the interest rates of various maturities for each country. Finally, we constructed dynamic out-of-sample forecasts of the term structure covering the period between May 2016 and August 2019 using the MSIAH(2)-VECM(p) model estimated, in order to assess further the usefulness of our nonlinear VECM characterization of the term structure.

Our study contributes to the literature in several ways. Firstly, to the best of our knowledge, none of the studies which have investigated the EH of the term structure of interest rates in BRICS countries have explored the possibility of parameter instability as a crucial factor which might explain the rejection of the restricted version of the cointegration space. Secondly, we extend the aforementioned studies by examining the term structure of interest rates over a more recent time span covering the period between January 2005 and August 2019 covering the global financial crisis started in 2008, the Brazil political crisis in 2014-2016, the China stock market bubble in 2015, and the Russian oil recession crisis in 2014. Thirdly, in order to assess further the usefulness of our nonlinear MS-VECM characterization of the term structure, dynamic out-of-sample forecasts of the term structure were constructed, over a more recent time span covering the period between May 2016 and August 2019, using the MSIAH(2)-VECM(p). Performing this analysis for the recent data is important to capture the effects of the aforementioned crisis above.

The study is organized as follows: In the next section, we discuss the related studies. In Section 3, we present the theories of term structure and the related statistical estimation issues. We also thoroughly present the Markov switching theory and the econometric approaches applied in extending the current framework towards incorporating vector error correction modeling. In Section 4, we present the data set, we conduct our exhaustive empirical analysis based on all estimated models, and we explicitly report the results from the estimated Markov switching vector error correction approach in an attempt to detect and explain the inherent nonlinearities and observed parameter instabilities. Moreover, we present the constructed dynamic out-of-sample forecasts of the term structure and the comparison of the forecasts produced by the MSIAH-VECM (p) to the forecasts generated by the VECM models comprising the same set of variables, as well as the forecasts generated by the term structure VECMs. In Section 5, we discuss the results and how they can be interpreted in perspective of previous studies and of the working hypotheses, along with future research directions. The final section summarizes and concludes our findings, including possible limitations of the study.

\section{Literature Review}

Ever since Fisher [9] postulated the Expectation Hypothesis (EH) of the term structure of interest rates, this appealing theory has been at the center of attention. Early studies investigated the relation of the EH with the term structure of bond yields. Fama and Bliss [10] and Campbell and Shiller [11], among others, show that expected excess returns on long-term bonds (term premia) do vary over time; moreover, it is possible to predict excess returns on bonds using observables, such as the forward rate or the term spread. Reference [12] presents the strongest evidence in support of the expectations hypothesis. He finds not only that the spread has statistically significant predictive power for excess returns on five year bonds but also that his data cannot reject the expectations theory.

Over the years, studies on the Expectations Hypothesis (EH) of term structure of interest rates have been conducted using various methodologies to test whether EH would hold or not. Campbell and Clarida [13] investigated the predictive ability and the co-movement of the risk premia in the term structure of money market interest rates in Europe, revealing that the term structure on European currencies revealed common factors with those of other non-European currencies. One year later, Campbell and Shiller [14] analyze the cointegrating interrelations between interest rates as implied by the expectations model of the term structure. References [15-18], studied the long run dynamics of the term structure of interest rates, focusing mostly on its cointegrating properties and therefore on building correction models. More recently, Clarida et al. [4] investigated the term structure of bond yields under a nonlinear framework using a nonlinear multivariate Vector Error Correction (VECM) model 
incorporating asymmetries in the error correction mechanism. They also studied the forecastability of the model they proposed against some linear benchmark models. Bekiros et al. [5] analyzed money market dynamics under a long-run equilibrium framework where commonly-monitored spreads serve as error correction terms, derived from a structural model incorporating autocorrelated risk premia, interest rate smoothing, and monetary policy feedback. They investigated the power of the expectations hypothesis theory of interest rates taking into account long-run deviations from equilibrium and inherent nonlinearities. They revealed short-run dynamic adjustments for the term structure of the USA, Germany, and the UK, which are subject to regime switches (The characteristics of the time series (mean and variance) stay the same during the whole time period under consideration but that is usually not the case. A time series can change behavior completely from one period to the next due to some structural changes. For example, a bond yield series can change its behavior drastically from trending to volatile after a macroeconomic shock. Regime shift models address this gap in basic time series modelling by segregating the time series into different "states". These models are also widely known as state-space models in time series literature. There are three types of models that are popularly used: Threshold models, Predictive models and Markov switching autoregressive models. Markov Switching Autoregressive Models assume the regime to be a 'hidden state' in which probability and characteristics are estimated using maximum likelihood estimation [19]). Moreover, they investigated the dynamic out-of-sample forecasts of the term structure to assess the effectiveness of nonlinear Markov Switching Vector Error Correction (MS-VECM) modeling in capturing the after-effects of the global crisis. Their results suggested that regime shifts in the mean and variance of the term structure may be intertwined with changes in fundamentals that play a role in driving interest rate regimes, in particular business cycle and inflation fluctuations.

BRICS countries are also in the core of the research interesting in testing the $\mathrm{EH}$ of the term structure. More specifically, Shelile [20] employed the Generalized Method Moments technique to investigate the predictive ability of the term structure of interest rates in five different periods of time, using data from South Africa spanning from 1970 to 2004. These five periods refer to the five different monetary policy frameworks that $\mathrm{S}$. Africa has experienced. The researcher reveal that in the highly regulated period, the term structure of interest rates poorly predicted real economic activity while in the periods where interest rates were deregulated, the term structure was a better predictor of real economic activity. More specifically, results show that term structure of interest rates have better forecastability the period from 2000 to 2004 when the financial markets are deregulated in South Africa due to the different monetary policy framework followed by monetary policy makers. Shivam and Jayadev [21] assessed the operational efficiency of the Indian money market and examined its structure by testing the validity of the $\mathrm{EH}$. Their results provide evidence that validates the $\mathrm{EH}$ in the Indian money market; implying that money market participants are able to predict changes in rates while choosing between various money market instruments. Beechey et al. [1] used cointegration methods to test the $\mathrm{EH}$ of the term structure of interest rates in fourteen developed and developing countries. In the majority of the countries, they showed a co-integrating relationship between long and short interest rates, supporting the EH. However, they did not find evidence of the EH in emerging economies, which were India and South Africa in this case. According to Reference [1], the likely reason for the absence of the $\mathrm{EH}$ in both countries is structural change. Interest rates in South Africa were accompanied by strong inflows of foreign capital and the shift to inflation targeting in 2000, and all of these changes are related to the decline in long term interest rates. The decline in long term interest rate over the life of the shorter term bond runs counter to the $\mathrm{EH}$, which insists that shorter term interest rates tend to rise over the life of the longer term interest rates [14]. Thus, the ability of the term structure to anticipate future movements in short term rates depends on the level and the volatility of the term premia. Shareef and Shijin [22] tried to analyze the implication of the expectation hypothesis for the Indian and USA term structure. Using Vector Autoregressive (VAR) estimates, they tried to test the dynamic interdependence of interest rates vis-à-vis FX fluctuations. They found evidence in line with the existence of the $\mathrm{EH}$, yet only in case of the emerging market. Consequently, 
the spread between the long and short rate of India is influenced by short-term rates and past values of the Indian spread.

\section{Methodology}

\subsection{Cointegration Analysis}

Hendry and Juselius $[23,24]$ investigated the properties of economic time series, such as random walks, which contained a unit root in their dynamics. They showed that, when data were non-stationary purely due to unit roots (integrated once, denoted I(1)), they could be brought back to stationarity by the linear transformation of differencing, as in $y_{t}-y_{t-1}=\Delta y_{t}$. For example, if the data generation process were the simplest random walk with an independent $(I N)$ error having mean zero and constant variance $\sigma_{e}^{2}$,

$$
y_{t}=y_{t-1}+e_{t} \text { where } e_{t} \sim \operatorname{IN}\left(0, \sigma_{e}^{2}\right)
$$

Subtracting $y_{t-1}$ from both sides would deliver $\Delta y_{t} \sim \operatorname{IN}\left(0, \sigma_{e}^{2}\right)$ which is certainly stationary. Such an analysis generalizes to (say) twice-integrated series, which are I(2), so must become I(0) after differencing them twice.

It is natural to enquire if other than linear transformations differencing will also induce stationarity. The answer is 'possibly', but unlike differencing, there is no guarantee that the outcome must be $\mathrm{I}(0)$ : cointegration analysis is designed to find linear combinations of variables that also remove unit roots.

Specifically, we assume that the data generating process of the I(1) stochastic variables is a Gaussian vector autoregressive model of finite order $p, \operatorname{VAR}(p)$, which can be expressed in a vector error-correction model (VECM) form as:

$$
\Delta y_{t}=v\left(s_{t}\right)+\Pi \mathrm{y}_{\mathrm{t}-1}+\sum_{\mathrm{i}=1}^{\mathrm{p}-1} \Gamma_{\mathrm{i}} \Delta \mathrm{y}_{\mathrm{t}-\mathrm{i}}+\varepsilon_{\mathrm{t}}
$$

In this specification $y$, is a $(n x 1)$ vector of endogenous variables, $v\left(s_{t}\right)$ is (the $K$-dimensional column vector of regime-dependent intercept terms, and $\varepsilon$ is a $(n x 1)$ multivariate random error which is identically and independently distributed. In addition, $\Gamma_{i}=-\sum_{j=i+1}^{p} \Pi_{j}$, where $\Pi_{i}^{\prime} \mathrm{s}$ are the matrices on the autoregressive part of the AR representation. The rank tests for cointegration involve the estimation of the rank, $r$, of $\Pi$ since this is equal to the number of cointegrating vectors. If $0<r<n$, then there are $r$ stationary linear combinations of the elements of $y$, and $n-r$ non-stationary common stochastic trends. In this case, there exist (nxr) matrices $\alpha$ and $\beta$ such that:

$$
\Pi=\alpha \beta^{\prime}
$$

where $\alpha$ is the adjustment coefficients matrix, and $\beta$ is the matrix of the cointegration vectors.

An equally important issue, along with the existence of at least one cointegration vector is the issue of the stability of such a relationship through time. Hansen and Johansen [6,7] have suggested methods for the evaluation of parameter constancy in cointegrated VAR models, formally using estimates obtained from the Johansen FIML recursive estimation technique. Specifically, three tests have been constructed under two VAR representations; By reestimating all parameters in each step and by reestimating only the long-run parameters $\alpha$ and $\beta$ and concentrating out the short-term dynamics using the full sample estimates of the parameters. The models are referred to as the "X-form" and "R-form", respectively (The usefulness of these two different representation forms stems from comparison implications. More specifically, major differences between the " $\mathrm{X}$-form" and "R-form" plots may signal problems with the short-run parameters). The first test, called the Rank Test, gives a sequence of trace statistics obtained from the recursive estimation of the model, scaled by the corresponding critical values, and we accept the null hypothesis that the chosen rank is maintained if it takes values greater than one, regardless of the sub-period it has been estimated for. The second test deals with the 
null hypothesis of constancy of the cointegration space for a given cointegration rank. Hansen and Johansen [6] proposed a likelihood ratio test that is constructed by comparing the likelihood function from each recursive sub-sample with the likelihood function from the full sample. The third test examines the constancy of the individual elements of the cointegrating vectors $\beta$, and it exploits the fact that there is a unique relationship between the eigenvalues and the cointegrating vectors. Therefore, when the cointegrating vectors have undergone a structural change, this will be reflected in the estimated eigenvalues. Hansen and Johansen [6,7] derived the asymptotic distribution, as well as the asymptotic variance, of the estimated eigenvalues.

\subsection{Asymmetric Markov Switching Equilibrium-Correction Modeling}

Regime-switching modeling characterizes non-linear data generating processes as being piecewise linear by restricting the processes to be linear in each regime, where the regime may be unobservable, and only a discrete number of regimes are feasible. The procedure extends Hamilton [24], who investigated the properties of regime switching econometric models in a univariate context. Krolzig [8] extended this framework to multivariate vector error correction models. Consider the MS-VAR process in its most general for:

$$
y_{t}=v\left(s_{t}\right)+\Pi_{1} y_{t-1}+\ldots+\prod_{k} y_{t-k}+\varepsilon_{t}, t=1,2, \ldots, T
$$

where $y_{t}$ is an $n$ dimensional time series vector observed at time $t$, and $T$ is the sample size. $v$ is the vector of intercepts, $\Pi_{1},{ }_{1}, \Pi_{p}$ are the matrices containing the autoregressive parameters, and $\varepsilon_{t}$ is a white noise vector process such that $\varepsilon_{t} \mid s_{t} \sim \operatorname{NID}\left(0, \Sigma\left(s_{t}\right)\right)$. The regime generating process is assumed to be an ergodic Markov chain with a finite number of states $s_{t} \in[1, \ldots, M]$ governed by transition probabilities $p_{i j}=\operatorname{Pr}\left(s_{t+1}=j / s_{t}=i\right)$ and $\sum_{j=1}^{M} p_{i j}=1$ for all $i, j \in\{1, \ldots, M\}$. The MS-VAR setting also allows for a variety of specifications. In Equation (7), the intercept term is assumed to vary with each state aside from the other parameters. Intercept switch specification is used in cases where the transition to the mean of the other state is assumed to follow a smooth path. An alternative representation is obtained by allowing the mean to vary with the state. This specification is useful in cases where a one-time jump is assumed in the mean after a change in regime.

This type of MS(M)-VAR $(p)$ model, which allows for regime shifts, both in the intercept, variance and covariance matrix, is the Markov switching intercept heteroskedastic VAR noted as MSIH-VAR by Krolzig [8]. The VEC representation of the MSIH-VAR(p) model, or MSIH-VECM(p-1) can be written as:

$$
\Delta y_{t}=v\left(s_{t}\right)+\Pi y_{t-1}+\sum_{i=1}^{p-1} \Gamma_{i} \Delta y_{t-i}+\varepsilon_{t}
$$

where $\Pi=-\left(I-\Pi_{1}-\ldots-\Pi_{p}\right)$ and $\Gamma_{i}=-\left(\Pi_{j+1}+\Pi_{j+2}+\ldots+\Pi_{p}\right)$ for $j=1,2, \ldots, p-1$

Given that $\Pi$ is not full rank, it can be written as the product of two rectangular matrices $\alpha$ and $\beta$ of order $n \times r$ such that $\Pi=a \beta^{\prime}$. The vector $\beta$ is the cointegrating vector and the vector $\alpha$ is the factor-loading (or speed of adjustment) vector. Hence, $r$ is the number of cointegrating vectors. Therefore, MSIH-VECM in Equation (5) can be written as

$$
\Delta y_{t}=v\left(s_{t}\right)+\alpha \beta^{\prime} y_{t-1}+\sum_{i=1}^{p-1} \Gamma_{i} \Delta y_{t-i}+\varepsilon_{t}
$$

As indicated by Clarida et al. [4] the asymmetric adjustment in interest rates, can be modeled within this framework. To capture the asymmetries in the data they write the above MSIH-VECM 
model by allowing differing speeds of adjustment to equilibrium depending on whether interest rates are above or below equilibrium, i.e., whether the $\beta^{\prime} y_{t-1}$ is negative or positive. Then,

$$
\Delta y_{t}=v\left(s_{t}\right)+\Psi_{t} \alpha^{+} \beta^{\prime} y_{t-1}+\left(I_{t}-\Psi_{t}\right) \alpha^{-} \beta^{\prime} y_{t-1}+\sum_{i=1}^{p-1} \Gamma_{i} \Delta y_{t-i}+\varepsilon_{t}
$$

where $I_{t}$ is an $r \times r$ identity matrix, and $\Psi_{t}$ is a $r \times r$ diagonal matrix whose $j$-th diagonal at time $t$ takes the value of unity or zero according to whether the lagged $j$-th deviation from the equilibrium, i.e., the $j$-th element of $\beta^{\prime} y_{t-1}$ is positive or negative, respectively. The model in Equation (7) is termed as MSIH Asymmetric VECM. The specifications in Equations (6)-(7) do not allow regime dependent behavior either for the speed of adjustment nor for the autoregressive coefficients (or short-run parameters). We can enrich the models considered by Clarida et al. [4] by allowing both types of regime switching. Firstly, we rewrite MSIH-VECM in Equation (6) as:

$$
\Delta y_{t}=v\left(s_{t}\right)+\alpha\left(s_{t}\right) \beta^{\prime} y_{t-1}+\sum_{i=1}^{p-1} \Gamma_{i}\left(s_{t}\right) \Delta y_{t-i}+\varepsilon_{t}
$$

This model can be noted as Markov-switching-intercept-autoregressive-heteroskedastic VECM (MSIAH-VECM). In this model, we retain the usual assumptions in the literature by supposing that, whereas the long-run parameters contained in the cointegration vector $\beta$ is regime-invariant, the speed of adjustment coefficients of vector $\alpha$ are regime-dependent. Then, considering an asymmetric behavior defined in Equation (7), we conclude to the following MSIAH Asymmetric VECM

$$
\Delta y_{t}=v\left(s_{t}\right)+\Psi_{t} \alpha^{+}\left(s_{t}\right) \beta^{\prime} y_{t-1}+\left(I-\Psi_{t}\right) \alpha^{-}\left(s_{t}\right) \beta^{\prime} y_{t-1}+\sum_{i=1}^{p-1} \Gamma_{i}\left(s_{t}\right) \Delta y_{t-i}+\varepsilon_{t}
$$

The estimation of the MSIAH-VECM models in Equations (7)-(9) can be carried out in three steps as suggested by Krolzig [8], and as applied by References [4,25-27]. The cointegration tests and the estimation of the parameters of the long-run relations can be achieved by the maximum likelihood (ML) approach within the context of VECMs, as outlined in References $[17,28]$. In the second step, the long-run parameter matrix $\boldsymbol{\beta}$ is estimated and is embedded in the above MS-VECM. The remaining parameters are estimated by using the expectation maximization algorithm of Reference [8].

\subsection{Forecastability Testing}

The statistical significance of the difference in forecast performance is tested with the statistic proposed by Reference [29]. Taking the pair of squared forecast errors from the two competing models $\left.e_{0, t}^{2}, e_{i, t}^{2}\right), t=1, \ldots \ldots, n$., the null hypothesis of equality of expected forecast performance is given by

$$
E\left(e_{0, t}^{2}, e_{i, t}^{2}\right)=0
$$

Defining $d_{t}=\left(e_{0, t^{\prime}}^{2} e_{i, t}^{2}\right), t=1, \ldots, n$, the test is based on the sample mean

$$
\bar{d}=n^{-1} \sum_{t=1}^{n} d_{t}
$$

As the sequence of forecast errors follows a moving average process of order $(h-1)$, i.e., implies that h-step-ahead forecast errors are serially correlated up to order $h-1$, the variance of $\bar{d}$ is asymptotically given

$$
V(\bar{d}) \approx n^{-1}\left[\gamma_{0}+2 \sum_{k=1}^{h-1} \gamma_{\kappa}\right],
$$


where $\gamma_{\kappa}$ is the $k$-th autocovariance of $d_{t}$. The Diebold-Mariano test statistic is then

$$
D M=[\hat{V}(\bar{d})]^{-1 / 2} \bar{d} \text { with } D M \sim N(0,1) .
$$

The test statistic is calculated for the 6-month and 12-month forecast horizon.

\section{Data and Empirical Results}

\subsection{Data and Preliminary Analysis}

We utilize a data set of weekly observations of the overnight and 1-, 3-, and 6- months, as well as of one year Treasury bills rates for Brazil, Russia, India, China, and South Africa, the so-called BRICS, spanning the period from January 2005 to August 2019 (Figure 1). In our empirical work, we carried out our estimations over the period January 2005 to May 2016, reserving the remaining data for out-of-sample forecasting tests (We used May 2016 as a break date following the results produced by Bai, J. and P. Perron [30] structural break point analysis. Results are available upon request). The descriptive statistics are presented in Table A1. Results show that skewness and kurtosis exhibit in all cases, with large standard deviations, especially in case of Brazil and Russia rates. The Dornik-Hansen test for all five countries is statistically significant, thereby indicating that the bond yield distributions are not normal, for all maturities. The series present nonlinear dependence due to clustering effects or conditional heteroscedasticity, as shown by the results of the ARCH LM-statistic and White's test, while the Durbin Watson statistic lies between 1.5 and 2.5, implying no autocorrelation. Next, we test for evidence of unit root behavior in each of the interest rates by calculating the standard Augmented Dickey-Fuller (ADF), Phillips-Perron, and Elliot, Rothenberg, and Stock point optimal (ERS) test statistics. In each case the number of lags was chosen such that no residual autocorrelation was evident in the regressions (Dickey and Fuller [31] showed that under the null hypothesis of a unit root, this statistic does not follow the conventional Student's t-distribution, and they derive asymptotic results and simulate critical values for various test and sample sizes. More recently, MacKinnon [32] implemented a much larger set of simulations than those tabulated by Dickey and Fuller. In addition, he estimated response surfaces for the simulation results, permitting the calculation of Dickey-Fuller critical values and $p$-values for arbitrary sample sizes. The simple Dickey-Fuller unit root test described above is valid only if the series is an AR(1) process. In the presence of higher order lags, the assumption of white noise disturbances $e_{t}$ is violated. The Augmented Dickey-Fuller (ADF) test constructs a parametric correction for higher-order correlation by assuming that each series follows an $\mathrm{AR}(\mathrm{p})$ process and adding $\mathrm{p}$ lagged difference terms of the dependent variable to the right-hand side of the test regression. Moreover, while the assumption that the series follows an autoregressive (AR) process may seem restrictive, Said and Dickey [33] demonstrated that the ADF test is asymptotically valid in the presence of a moving average (MA) component, provided that sufficient lagged difference terms are included in the test regression. An alternative (nonparametric) method of controlling for serial correlation when testing for a unit root was proposed by Reference [34]. The PP method estimates the non-augmented DF test and modifies the $\mathrm{t}$-ratio so that serial correlation does not affect the asymptotic distribution of the test statistic. The ERS point optimal test is based on the quasi-differencing regression. The critical values for the ERS test statistic are computed by interpolating the simulation results provided by Reference [35]). As shown in Table A2, we were unable to reject the unit root null hypothesis at all nominal levels of significance. Moreover, differencing the series did appear to induce stationarity in all cases. Hence, each of the examined time series is a realization from an integrated stochastic process of order one, which suggests that testing for cointegration between the five interest rates is the logical next step. 


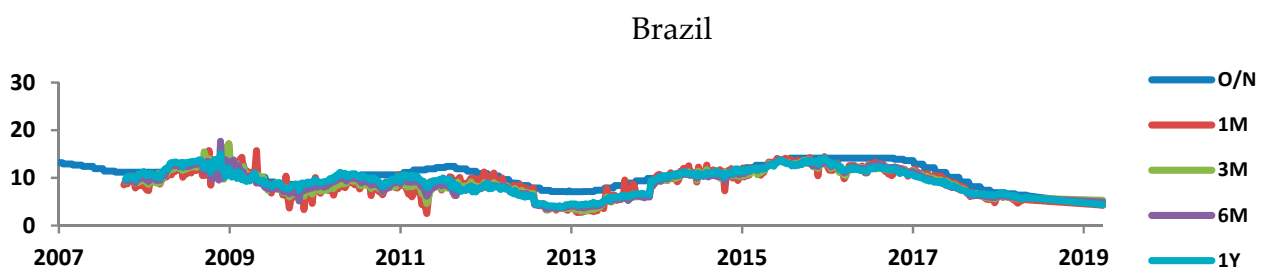

Russia

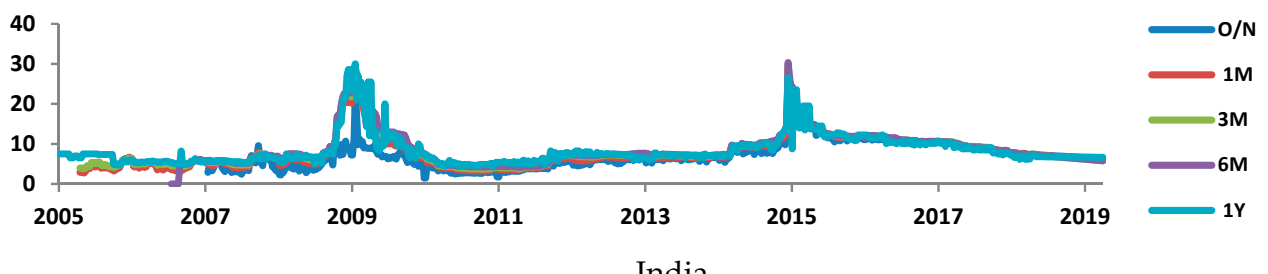

India
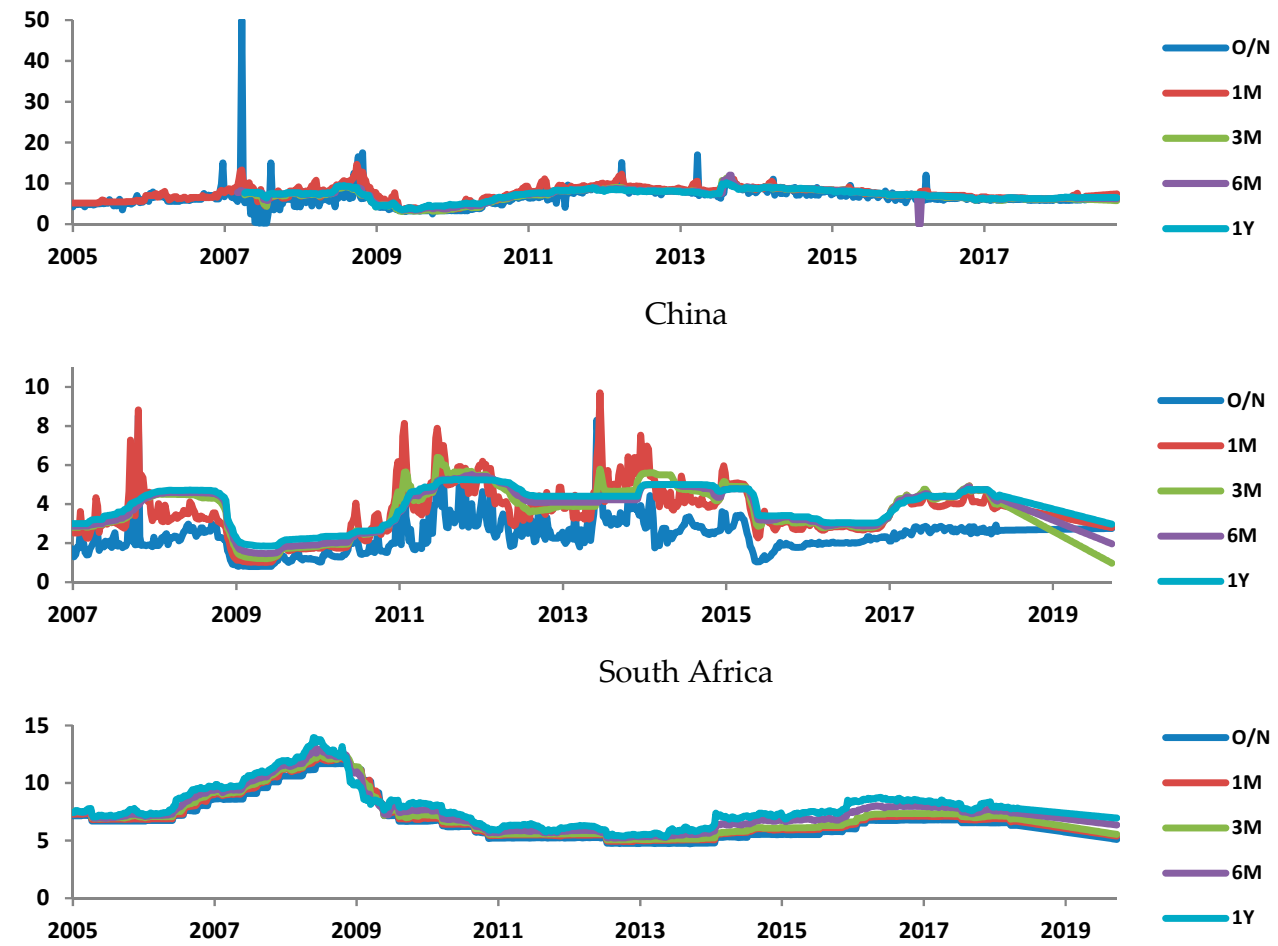

Figure 1. Treasury bills interest rates for BRICS countries. Note: $\mathrm{O} / \mathrm{N}, 1 \mathrm{M}, 3 \mathrm{M}, 6 \mathrm{M}, 1 \mathrm{Y}$ denote the overnight and one-, three-, six- months and one year Treasury bills rates for Brazil, Russia, India, China, and South Africa, spanning the period from January 2005 to August 2019.

We use the Johansen maximum likelihood procedure under a VAR specification for $y_{t}=\left[i_{0, t}, i_{4, t}, i_{13, t}, i_{26, t}, i_{52, t}\right]^{\prime}$ and an unrestricted constant term (We allowed for a maximum lag length of 24 and chose for each country the appropriate lag length on the basis of conventional information criteria [36]. More specifically we chose 6 lags for the China, Russia, and India and 4 lags for Brazil and S. Africa. We have also tested for a restricted constant term, with no statistically significant results at the $5 \%$ significance level). On the basis of the Johansen likelihood test statistic for the cointegrating rank as reported in Table A3 (see Appendix B) for India and South Africa, we could not reject the hypothesis of four independent cointegrating vectors against the alternative of five at the $5 \%$ significant level, whilst, for the Brazil, China, and Russia, we could not reject the hypothesis of three independent cointegrating vectors against the alternative of four at $5 \%$ significant level. We conclude that there are exactly four cointegrating relationships between the five rates for India and South Africa and three cointegrating vectors for the Brazil, China, and Russia. 
In parallel with the existence of at least one cointegration vector, we test the issue of the stability of such a relationship over time. Following Reference [6,7], we try to evaluate the parameter constancy in the cointegrated VAR models, formally using estimates obtained from the Johansen FIML technique. Our cointegration results are robust to the presence of structural breaks in the cointegrating rank, as allowed for in the Hansen-Johansen procedure. Figures A1-A4 (see Appendix A) present the results by the tests for the structural stability of our estimated cointegrating systems. In Figures A1 and A2 (see Appendix A), the trace test under the "X-representation" shows that a cointegration space of four vectors for India and South Africa and a cointegration space of three vectors for the Brazil, China, and Russia is established from the beginning of the recursive exercise and remains the same up until 2010. As expected, this is not the case with the "R-representation" since the short-run parameters are not allowed to change. The test for the constancy of the cointegration space is equally adequate. As shown in Figures A3 and A4 (see Appendix A), the graphs are scaled by the $5 \%$ critical value and therefore the null of stability is rejected if the test value exceeds the value of one. In the case of Brazil, we observe that the values of the test statistic remain below the value of one from the beginning of the recursive exercise and remain the same up to the end. Contrary to Brazil, for India and South Africa, we observe that the values of the test statistic exceed the value of one from 2009 to 2012, while, for Russia and China, the values of the test statistic exceed the value of one from the beginning of the exercise until 2010. In general, all plots show very clearly a break, for several months, around the global financial crisis period of 2008-2012.

Following Reference $[16,17,37]$, we test the exclusion of the variables in the long-run relations. When analyzing the cointegrated VAR model sometimes, only a subset of variables is needed in the cointegration space. Specifically, in Table 1 results shown that there is no evidence to exclude any variable for India and South Africa at four cointegrating relations and for the Brazil, China, and Russia at three cointegrating relationships.

Table 1. Variable exclusion test.

\begin{tabular}{|c|c|c|c|c|c|c|c|}
\hline$r$ & DGF & $5 \%$ C.V. & $i_{0, t}$ & $i_{4, t}$ & $i_{13, t}$ & $i_{26, t}$ & $i_{52, t}$ \\
\hline \multicolumn{8}{|c|}{ Brazil } \\
\hline$r$ & DGF & $5 \%$ C.V. & $i_{0, t}$ & $i_{4, t}$ & $i_{13, t}$ & $i_{26, t}$ & $i_{52, t}$ \\
\hline 3 & 3 & 7.815 & $\begin{array}{c}4.827 \\
{[0.005]}\end{array}$ & $\begin{array}{l}102.055 \\
{[0.000]}\end{array}$ & $\begin{array}{l}113.737 \\
{[0.000]}\end{array}$ & $\begin{array}{l}66.856 \\
{[0.000]}\end{array}$ & $\begin{array}{l}40.459 \\
{[0.000]}\end{array}$ \\
\hline \multicolumn{8}{|c|}{ Russia } \\
\hline$r$ & DGF & $5 \%$ C.V. & $i_{0, t}$ & $i_{4, t}$ & $i_{13, t}$ & $i_{26, t}$ & $i_{52, t}$ \\
\hline 3 & 3 & 7.815 & $\begin{array}{l}61.223 \\
{[0.000]}\end{array}$ & $\begin{array}{l}32.425 \\
{[0.000]}\end{array}$ & $\begin{array}{c}41.400 \\
{[0.000]}\end{array}$ & $\begin{array}{l}50.983 \\
{[0.000]}\end{array}$ & $\begin{array}{l}90.654 \\
{[0.000]}\end{array}$ \\
\hline \multicolumn{8}{|c|}{ India } \\
\hline$r$ & DGF & 5\% C.V. & $i_{0, t}$ & $i_{4, t}$ & $i_{13, t}$ & $i_{26, t}$ & $i_{52, t}$ \\
\hline 4 & 4 & 9.488 & $\begin{array}{l}59.244 \\
{[0.000]}\end{array}$ & $\begin{array}{l}36.306 \\
{[0.000]}\end{array}$ & $\begin{array}{l}70.259 \\
{[0.000]}\end{array}$ & $\begin{array}{l}91.937 \\
{[0.025]}\end{array}$ & $\begin{array}{l}57.097 \\
{[0.044]}\end{array}$ \\
\hline \multicolumn{8}{|c|}{ China } \\
\hline$r$ & DGF & $5 \%$ C.V. & $i_{0, t}$ & $i_{4, t}$ & $i_{13, t}$ & $i_{26, t}$ & $i_{52, t}$ \\
\hline 3 & 3 & 7.815 & $\begin{array}{l}35.110 \\
{[0.000]}\end{array}$ & $\begin{array}{l}31.790 \\
{[0.002]}\end{array}$ & $\begin{array}{c}17.331 \\
{[0.001]}\end{array}$ & $\begin{array}{c}7.192 \\
{[0.036]}\end{array}$ & $\begin{array}{c}3.202 \\
{[0.002]}\end{array}$ \\
\hline \multicolumn{8}{|c|}{ South Africa } \\
\hline$r$ & DGF & $5 \%$ C.V. & $i_{0, t}$ & $i_{4, t}$ & $i_{13, t}$ & $i_{26, t}$ & $i_{52, t}$ \\
\hline 4 & 4 & 9.488 & $\begin{array}{c}457.514 \\
{[0.000]}\end{array}$ & $\begin{array}{l}93.462 \\
{[0.000]}\end{array}$ & $\begin{array}{c}81.136 \\
{[0.000]}\end{array}$ & $\begin{array}{c}65.032 \\
{[0.000]}\end{array}$ & $\begin{array}{l}79.297 \\
{[0.000]}\end{array}$ \\
\hline
\end{tabular}

Notes: The $p$-values are in brackets.

Furthermore, we test the weak exogeneity for the Long-Run parameters (Weak exogeneity is a hypothesis about the rows of $\alpha$ when the parameters of interest are the long-run parameters $\alpha$ and $\beta$. We tested the weak exogeneity for the Long-Run parameters following the hypothesis testing proposed by Reference [28], imposing zero-rows on the matrix of the Long-Run parameters estimated by the 
VECM models). By conditioning on weakly exogenous variables, the rest of the system is likely to "behave" more robustly, statistically speaking. Results in Table 2 show that, for China and Russia for three cointegrating vector relations, the $6 \mathrm{M}$ T-bill and the 1Y T-bill can each be considered weakly exogenous at the $5 \%$ significance level.

Table 2. Weak exogeneity testing.

\begin{tabular}{|c|c|c|c|c|c|c|c|}
\hline$r$ & DGF & $5 \%$ C.V. & $i_{0, t}$ & $i_{4, t}$ & $i_{13, t}$ & $i_{26, t}$ & $i_{52, t}$ \\
\hline \multicolumn{8}{|c|}{ Brazil } \\
\hline$r$ & DGF & $5 \%$ C.V. & $i_{0, t}$ & $i_{4, t}$ & $i_{13, t}$ & $i_{26, t}$ & $i_{52, t}$ \\
\hline 3 & 3 & 7.815 & $\begin{array}{c}17.069 \\
{[0.001]}\end{array}$ & $\begin{array}{l}49.069 \\
{[0.000]}\end{array}$ & $\begin{array}{l}48.079 \\
{[0.000]}\end{array}$ & $\begin{array}{c}17.883 \\
{[0.000]}\end{array}$ & $\begin{array}{c}7.307 \\
{[0.000]}\end{array}$ \\
\hline & \multicolumn{7}{|c|}{ Russia } \\
\hline$r$ & DGF & $5 \%$ C.V. & $i_{0, t}$ & $i_{4, t}$ & $i_{13, t}$ & $i_{26, t}$ & $i_{52, t}$ \\
\hline 3 & 3 & 7.815 & $\begin{array}{c}14.690 \\
{[0.000]}\end{array}$ & $\begin{array}{c}5.719 \\
{[0.006]}\end{array}$ & $\begin{array}{c}7.399 \\
{[0.040]}\end{array}$ & $\begin{array}{c}6.610 \\
{[0.085]}\end{array}$ & $\begin{array}{l}46.299 \\
{[0.085]}\end{array}$ \\
\hline & \multicolumn{7}{|c|}{ India } \\
\hline$r$ & DGF & 5\% C.V. & $i_{0, t}$ & $i_{4, t}$ & $i_{13, t}$ & $i_{26, t}$ & $i_{52, t}$ \\
\hline 4 & 4 & 9.488 & $\begin{array}{l}39.865 \\
{[0.000]}\end{array}$ & $\begin{array}{l}25.515 \\
{[0.000]}\end{array}$ & $\begin{array}{l}16.506 \\
{[0.002]}\end{array}$ & $\begin{array}{l}90.039 \\
{[0.000]}\end{array}$ & $\begin{array}{l}11.469 \\
{[0.022]}\end{array}$ \\
\hline & \multicolumn{7}{|c|}{ China } \\
\hline$r$ & DGF & $5 \%$ C.V. & $i_{0, t}$ & $i_{4, t}$ & $i_{13, t}$ & $i_{26, t}$ & $i_{52, t}$ \\
\hline 3 & 3 & 7.815 & $\begin{array}{c}40.839 \\
{[0.000]}\end{array}$ & $\begin{array}{l}19.305 \\
{[0.002]}\end{array}$ & $\begin{array}{c}6.484 \\
{[0.003]}\end{array}$ & $\begin{array}{c}8.240 \\
{[0.061]}\end{array}$ & $\begin{array}{c}4.553 \\
{[0.208]}\end{array}$ \\
\hline & \multicolumn{7}{|c|}{ South Africa } \\
\hline$r$ & DGF & $5 \%$ C.V. & $i_{0, t}$ & $i_{4, t}$ & $i_{13, t}$ & $i_{26, t}$ & $i_{52, t}$ \\
\hline 4 & 4 & 9.488 & $\begin{array}{l}458.202 \\
{[0.000]}\end{array}$ & $\begin{array}{l}124.129 \\
{[0.000]}\end{array}$ & $\begin{array}{c}117.759 \\
{[0.000]}\end{array}$ & $\begin{array}{c}90.208 \\
{[0.000]}\end{array}$ & $\begin{array}{l}27.627 \\
{[0.000]}\end{array}$ \\
\hline
\end{tabular}

Following References [38,39], we test the over-identifying restrictions on the $\beta$ matrix of the cointegrating coefficients. Results in Table 3 suggest that the departure from the over identifying restrictions are not statistically significant at conventional test sizes. More specifically, for India and South Africa, the estimated VECM identified a one-to-one long-run relationship between (i) overnight and 1-month Treasury bill, (ii) the overnight and the 3-months bill, (iii) the overnight and the 6-months Treasury bill, and (vi) the overnight and the 1-year bill, whilst, for Brazil, China, and Russia, the VECM identified a one-to-one long-run relationship between the (i) overnight and 1-month Treasury bill, (ii) the overnight and the 3-months bill, and the (iii) the overnight and the 6-months Treasury bill.

Table 3. Long-run structure restrictions.

\begin{tabular}{cccc}
\hline Vector & Brazil & Russia & India \\
\hline Vector 1 & 3M T-bill-1M T-bill & 1 Year T-bill-1M T-bill & 1M T-bill-Overnight T-bill \\
Vector 2 & 6M T-bill-1M T-bill & 1 Year T-bill-3M T-bill & 3M T-bill-Overnight T-bill \\
Vector 3 & 1 Year T-bill-1M T-bill & 1 Year T-bill-6M T-bill & 6M T-bill-Overnight T-bill \\
Vector 4 & CHISQR(6)=1.560 & CHISQR(6) 8.941 & 1 Year T-bill-Overnight T-bill \\
Bartletts Correction Test & CHISQR(4) 2.833 [0.586] \\
& China & [0.177] & \\
Vector 1 & 1M T-bill-Overnight & 1M T-bill-Overnight & \\
& T-bill & T-bill & \\
Vector 2 & 3M T-bill-Overnight & 3M T-bill-Overnight & \\
Vector 3 & T-bill & T-bill & \\
& 6M T-bill-Overnight & 6M T-bill-Overnight & \\
Vector 4 & T-bill & T-bill & \\
& & 1 Year T-bill-Overnight & \\
\hline \multirow{2}{*}{ Bartletts Correction Test } & CHISQR(6)=3.051 & CHISQR(4)=6.695 & \\
& {$[0.802]$} & {$[0.153]$} & \\
\hline
\end{tabular}

Notes: The number in brackets denote the $p$-value for $x^{2}(g)$ under the null, where $g$ is the number of restrictions; the imposing restriction is rejected for $p$-values $<0.05$. 


\subsection{MSIAH-VECM Estimation Results}

Taking into account the results unveiled above, we then try to investigate their short-run time-varying adjustments. Subsequently, we wish to distinguish whether the sign of the shock causes a different adjustment speed toward the equilibrium state. Many times, it is reported that negative shocks might take longer to adjust than positive shocks. In Table 4, we test our VECM modeling specifications against their corresponding asymmetric VECM and nonlinear MS-VECM alternatives, assuming the presence of nonlinearity, as considered in Reference [4].

Table 4. Linearity testing.

\begin{tabular}{ccc}
\hline Countries & LR & $p$-Value \\
\hline Brazil & 7222.0 & $<0.01$ \\
Russia & 6077.5 & $<0.01$ \\
India & 9914.1 & $<0.01$ \\
China & $16,099.0$ & $<0.01$ \\
South Africa & $16,594.0$ & $<0.01$ \\
\hline
\end{tabular}

Notes: $L R$ is a likelihood ratio test of the symmetrical null hypothesis, i.e., the restricted model tested is the symmetric linear $\operatorname{VECM}(p)$ vs. the alternative $\operatorname{VECM}(p)$, which allows for asymmetric equilibrium correction. The test is constructed as $2\left(\ln L^{*} / \ln L\right)$, where $L^{*}$ and $L$ represent the unconstrained and constrained maximum likelihood, respectively. The test statistic is asymptotically distributed as $x^{2}(g)$ under the null hypothesis, with $g$ number of restrictions.

Next, we apply the "bottom-up" procedure designed to detect Markovian shifts in order to select the most adequate and robust characterization of a two-regime $p_{t h}$-order MS-VECM set-up for the BRICS countries (Essentially, the bottom-up approach comprises starting with a simple but statistically reliable Markov-switching model by restricting the effects of regime shifts on a limited number of parameters, and then checking the model against alternatives; for a technical discussion, see Reference [8]). We not only test the hypothesis of no regime switching in the intercept but also in the variance-covariance matrix, as well as the autoregressive parameters using the $L R$ tests suggested by Reference [8]. The results in Table 5 indicate a strong rejection of the null of no regime dependence in the intercept $\left(L R_{1}\right)$ and in the variance-covariance matrix $\left(L R_{2}\right)$. Therefore, an MS-VECM allows for shifts in both the intercept and the variance-covariance matrix; hence, an $\operatorname{MSIH}(2)-\operatorname{VECM}(p)$ can be considered the most appropriate econometric model.

After testing for regime-conditional intercept and homoskedasticity, we attempt to robustly select the most parsimonious MSIH-VECM specification that represents the dynamic relationship between the interest rates examined. Firstly, we consider a maximum lag length of 12 for the VAR in levels and a maximum lag length of 11 in the VECM formulation and test the null of an MSIH(2)-VECM(1) vis-à-vis an alternative $\operatorname{MSIAH}(2)-\operatorname{VECM}(p)$, as it can be seen by the inspection of the $\left(L R_{3}\right)$ tests.

Overall, we are able to reject this null at standard significance levels in all cases. For each of the five countries, we use an asymmetric MSIAH-VECM with two regimes, which was found to provide with an accurate characterization of the dynamics of the term structure. The MS-VECM formulation captures a regime shift related to the Global financial crisis in 2010, for the five countries, as shown in Figures A5-A9 (see Appendix A). The results provide regime classification information expressed by the smoothed probabilities of being in the high and/or low volatility regime. The regime shifts occur in the intercept, in the variance-covariance matrix and in the autoregressive parameters. For each of the countries considered, the regime with a higher variance corresponds to periods wherein the average interest rate at each maturity is relatively high; this is also reflected by the fact that the high-variance regime exhibits estimated intercept terms greater than the intercept in the low-variance regime accordingly. Thus, the two regimes may be seen as reflecting a higher mean and variance for the investigated interest rates in one regime and - on average - lower and less volatile fluctuations for the rates' series in the other regime. The identification of the regimes, also in accordance with the stylized facts, can be rationalized in light of a change in the monetary-fiscal policy mix from fiscally-led 
to monetary-led. In particular, under Regime 0 (low-volatility regime) probably the higher deficits lead to a higher average inflation, whilst the real interest rates remained low as the monetary authority did not respond aggressively to inflation. Hence, Regime 0 could be associated with a fiscally-led policy and Regime 1 with a monetary-led one, respectively.

Table 5. Bottom-up process.

\begin{tabular}{|c|c|c|}
\hline Restricted Model & Unrestricted Model & LRs \\
\hline \multicolumn{3}{|c|}{ Brazil } \\
\hline 648.983 & 740.566 & $\begin{array}{c}L R_{1} \\
1.339 *\end{array}$ \\
\hline 740.566 & 973.677 & $\begin{array}{c}L R_{2} \\
1.509 \text { * }\end{array}$ \\
\hline 973.677 & 1344.121 & $\begin{array}{c}L R_{3} \\
2.093 \text { * }\end{array}$ \\
\hline \multicolumn{3}{|c|}{ Russia } \\
\hline 546.908 & 780.733 & $\begin{array}{c}L R_{1} \\
1.784 \text { * }\end{array}$ \\
\hline 780.733 & 937.404 & $\begin{array}{c}L R_{2} \\
1.900 *\end{array}$ \\
\hline 937.404 & 1067.357 & $\begin{array}{c}L R_{3} \\
2.037 \text { * }\end{array}$ \\
\hline \multicolumn{3}{|c|}{ India } \\
\hline 786.245 & 984.914 & $\begin{array}{c}L R_{1} \\
1.786 \text { * }\end{array}$ \\
\hline 984.914 & 1136.978 & $\begin{array}{c}L R_{2} \\
1.948 \text { * }\end{array}$ \\
\hline 1136.978 & 1432.405 & $\begin{array}{c}L R_{3} \\
2.065 \text { * }\end{array}$ \\
\hline \multicolumn{3}{|c|}{ China } \\
\hline 2836.182 & 4222.057 & $\begin{array}{c}L R_{1} \\
1.240 *\end{array}$ \\
\hline 4222.057 & 4365.062 & $\begin{array}{c}L R_{2} \\
1.767 *\end{array}$ \\
\hline 4365.062 & 4892.870 & $\begin{array}{c}L R_{3} \\
1.985 *\end{array}$ \\
\hline \multicolumn{3}{|c|}{ South Africa } \\
\hline 2988.157 & 3800.397 & $\begin{array}{c}L R_{1} \\
1.585 \text { * }\end{array}$ \\
\hline 3800.397 & 7260.960 & $\begin{array}{c}L R_{2} \\
1.732 \text { * }\end{array}$ \\
\hline 7260.960 & 7278.7834 & $\begin{array}{c}L R_{3} \\
1.916 \text { * }\end{array}$ \\
\hline
\end{tabular}

Notes: The $L R_{1}, L R_{2}$, and $L R_{3}$ are the test statistics and the $p$-values of the null hypothesis of no regime-dependent intercept, no regime-dependent variance-covariance matrix, and of $\operatorname{MSIH}(2)-\operatorname{VECM}(1)$ vs. $\operatorname{MSIH}(2)-\operatorname{VECM}(p)$, respectively. Each of $L R_{1}, L R_{2}$, and $L R_{3}$ is constructed as $2(\ln L * / \ln L)$, where the $L *$ and $L$ represent the unconstrained and constrained maximum likelihood, respectively. These test statistics are asymptotically distributed as $x^{2}(g)$, where $g$ the number of restrictions; ${ }^{*}$ denotes statistical significance at $5 \%$ level.

Next, Table 6 displays the estimates for the probability of staying in a regime and the estimated duration for each of the examined countries. The standard deviations in the first regime are substantially smaller than those of the second one for the three countries; hence, we can call Regime 1 the low-volatility regime, whilst Regime 2 the high-volatility state. Judging by those estimates, for Brazil, we find a $96.7 \%$ probability that a low volatility regime will be followed by a similar one with an estimated duration of 23.85 months, while the corresponding probability for the high volatility period is $40 \%$ with an estimated duration of 1.66 months. For Russia, there is a $93.5 \%$ probability that a low volatility state follows a previous same regime with a duration of 15.38 months and a $79.7 \%$ persistence in the high volatility regime with an estimated duration of 4.95 months. For India, there is a $90 \%$ probability 
that a low volatility state follows a previous same regime with a duration of 10.5 months and a $70 \%$ persistence in the high volatility regime with an estimated duration of 3 months. For China, there is an $85 \%$ probability that a low volatility state follows a previous same regime with duration of 6.7 months and a $95 \%$ persistence in the high volatility regime with an estimated duration of 3.34 months. Lastly, for the South Africa, we find a $97.6 \%$ probability that a low volatility regime will be followed by a similar one lasting 41.46 months, while the corresponding probability for the high volatility period is $5 \%$ with an estimated duration of nearly 1.06 months.

Table 6. Markov-switching-intercept-autoregressive-heteroskedastic (MSIAH)(2)-VECM(p) results for BRICS.

\begin{tabular}{|c|c|c|c|c|c|}
\hline $\begin{array}{c}\text { Transition } \\
\text { Probabilities }\end{array}$ & Regime 1 & Regime 2 & Duration & Regime 1 & Regime 2 \\
\hline \multicolumn{6}{|c|}{ Brazil MSIAH(2)-VECM(2) } \\
\hline Regime 1 & 0.957 & 0.599 & Duration & 23.25 & 1.66 \\
\hline Regime 2 & 0.042 & 0.400 & & & \\
\hline \multicolumn{6}{|c|}{ Russia MSIAH(2)-VECM(1) } \\
\hline Regime 1 & 0.935 & 0.202 & Duration & 15.38 & 4.95 \\
\hline Regime 2 & 0.064 & 0.797 & & & \\
\hline \multicolumn{6}{|c|}{ India MSIAH(2)-VECM(1) } \\
\hline Regime 1 & 0.905 & 0.329 & Duration & 10.52 & 3.039 \\
\hline Regime 2 & 0.094 & 0.700 & & & \\
\hline \multicolumn{6}{|c|}{ China MSIAH(2)-VECM(1) } \\
\hline Regime 1 & 0.851 & 0.299 & Duration & 6.711 & 3.344 \\
\hline Regime 2 & 0.148 & 0.949 & & & \\
\hline \multicolumn{6}{|c|}{ South Africa We define MSIAH(2)-VECM(1) } \\
\hline Regime 1 & 0.976 & 0.942 & Duration & 41.66 & 1.061 \\
\hline Regime 2 & 0.023 & 0.057 & & & \\
\hline
\end{tabular}

Notes: "BRICS" countries label refers to a select group of five large, developing countries (Brazil, Russia, India, China, and South Africa). The "Duration" incorporates the expected length of each regime calculated as $1 /(1-P(1,1)$ for the 1st regime and $1 / P(1,2)$ for the 2 nd regime.

\subsection{Forecasting the Term Structure of Interest Rates with the MSIAH-VECM}

Trying to assess further the usefulness of our nonlinear VECM characterization of the term structure, we constructed dynamic out-of-sample forecasts of the term structure using the $\operatorname{VECM}(\mathrm{p})$ and MSIAH(2)-VECM(p), which are estimated and described in the previous sections. More specifically, we performed forecasting exercises for May 2016 to August 2019 with forecast horizons 6 and 12 months ahead. The out-of-sample forecasts for a given horizon were constructed recursively, conditional only on information up to the date of the forecast and with successive re-estimation as the date on which forecasts are conditioned moves through the data set. Forecast accuracy is evaluated computing the DM-statistic to investigate the statistical significance of the differential predictability between VECMs and MSIAH(2)-VECMs in a pairwise fashion. The predictability results are reported in Table 7.

Starting with Brazil, we observe that the D-M test shows a statistically significant differential predictability between the VECMs and the MSIAH(2)-VECM's pairs. MSIAH(2)-VECM's have better predictive ability from VECMs for the majority of interest rates, with exceptions for the 6-month T-bills and 1-year Treasury bill for 6 and 12 months forecasting horizon. For Russia, the D-M results show that MSIAH(2)-VECM's have better predictive ability from VECMs for the majority of interest rates, with exceptions for the 6-month T-bills and 1-year Treasury bill for 6 months forecasting horizon, while, for the 12 months, forecasting horizon D-M results show that MSIAH(2)-VECM's have better predictive ability from VECMs only for overnight T-bills. For India, the D-M results show that MSIAH(2)-VECM's outperformed VECMs for overnight and 1-year Treasury bills for both forecasting horizons. For China, the D-M results show that MSIAH(2)-VECM's have better predictive ability from VECMs for overnight and 3-month Treasury bills for 6 months forecasting horizon while for the 12 months forecasting horizon D-M results show that MSIAH(2)-VECM's have better predictive 
ability from VECMs only for overnight T-bills. Finally, for the South Africa rates, the results show that nonlinear MSIAH(2)-VECMs outrank the linear VECM models. The D-M test results show that MSIAH(2)-VECM models outperform the linear VECM models for the overnight, 3-month and 1-year Treasury bill forecasts for 6 months forecasting horizon while for the 12 months forecasting horizon D-M results show that MSIAH(2)-VECM's have better predictive ability from VECMs for overnight and 1-month T-bills.

Table 7. Forecasting accuracy-Diebold-Marianno tests.

\begin{tabular}{|c|c|c|c|c|c|c|}
\hline Hours & $\begin{array}{c}\text { VECMs } \\
\text { MSIAH(2)-VECMs }\end{array}$ & $i_{0, t}$ & Country & $i_{13, t}$ & $i_{26, t}$ & $i_{52, t}$ \\
\hline \multirow{2}{*}{$h$} & \multicolumn{6}{|c|}{ Brazil } \\
\hline & & $i_{0, t}$ & $i_{4, t}$ & $i_{13, t}$ & $i_{52, t}$ & $i_{26, t}$ \\
\hline \multirow[b]{2}{*}{6} & $\operatorname{VECM}(6)$ & 0.002 & 0.001 & 0.001 & 0.302 & 0.435 \\
\hline & MSIAH(2)-VECM(2) & 0.998 & 0.999 & 0.999 & 0.798 & 0.565 \\
\hline \multirow{3}{*}{12} & $\operatorname{VECM}(6)$ & 0.045 & 0.099 & 0.036 & 0.399 & 0.306 \\
\hline & MSIAH(2)-VECM(2) & 0.955 & 0.901 & 0.974 & 0.701 & 0.693 \\
\hline & \multicolumn{6}{|c|}{ Russia } \\
\hline \multirow{3}{*}{6} & & $i_{0, t}$ & $i_{4, t}$ & $i_{13, t}$ & $i_{26, t}$ & $\mathrm{i}_{52, \mathrm{t}}$ \\
\hline & $\operatorname{VECM}(7)$ & 0.002 & 0.002 & 0.010 & 0.120 & 0.366 \\
\hline & MSIAH(2)-VECM(1) & 0.998 & 0.998 & 0.990 & 0.880 & 0.634 \\
\hline \multirow{4}{*}{12} & $\operatorname{VECM}(7)$ & 0.069 & 0.110 & 0.211 & 0.412 & 0.485 \\
\hline & MSIAH(2)-VECM(1) & 0.931 & 0.890 & 0.789 & 0.598 & 0.515 \\
\hline & \multicolumn{6}{|c|}{ India } \\
\hline & & $i_{0, t}$ & $i_{4, t}$ & $i_{13, t}$ & $i_{26, t}$ & $i_{52, t}$ \\
\hline \multirow{2}{*}{6} & $\operatorname{VECM}(6)$ & 0.002 & 0.120 & 0.170 & 0.112 & 0.019 \\
\hline & MSIAH(2)-VECM(1) & 0.998 & 0.880 & 0.830 & 0.887 & 0.981 \\
\hline \multirow{4}{*}{12} & $\operatorname{VECM}(6)$ & 0.095 & 0.110 & 0.190 & 0.340 & 0.078 \\
\hline & MSIAH(2)-VECM(1) & 0.905 & 0.790 & 0.710 & 0.660 & 0.922 \\
\hline & \multicolumn{6}{|c|}{ China } \\
\hline & & $i_{0, t}$ & $i_{4, t}$ & $i_{13, t}$ & $\mathrm{i}_{26, \mathrm{t}}$ & $i_{52, t}$ \\
\hline \multirow{2}{*}{6} & $\operatorname{VECM}(6)$ & 0.056 & 0.455 & 0.030 & 0.337 & 0.445 \\
\hline & MSIAH(2)-VECM(1) & 0.944 & 0.545 & 0.970 & 0.663 & 0.555 \\
\hline \multirow{4}{*}{12} & $\operatorname{VECM}(6)$ & 0.090 & 0.499 & 0.111 & 0.401 & 0.501 \\
\hline & MSIAH(2)-VECM(1) & 0.910 & 0.501 & 0.889 & 0.599 & 0.499 \\
\hline & \multicolumn{6}{|c|}{ South Africa } \\
\hline & & $i_{0, t}$ & $i_{4, t}$ & $i_{13, t}$ & $\mathrm{i}_{26, \mathrm{t}}$ & $\mathrm{i}_{52, \mathrm{t}}$ \\
\hline \multirow{2}{*}{6} & $\operatorname{VECM}(1)$ & 0.010 & 0.011 & 0.101 & 0.289 & 0.089 \\
\hline & MSIAH(2)-VECM(1) & 0.990 & 0.989 & 0.899 & 0.711 & 0.901 \\
\hline \multirow[b]{2}{*}{12} & $\operatorname{VECM}(1)$ & 0.049 & 0.070 & 0.211 & 0.301 & 0.112 \\
\hline & MSIAH(2)-VECM(1) & 0.951 & 0.930 & 0.789 & 0.699 & 0.888 \\
\hline
\end{tabular}

Notes: D-M represents $p$-values of the Diebold-Mariano forecasting accuracy tests. P-values will (by construction) always add up to one. Null hypothesis of the first line indicates that $\operatorname{VECM}(p)$ and $\operatorname{MSIAH}(2)-\operatorname{VECM}(p)$ have the same forecasting ability with the alternative that $\operatorname{MSIAH}(2)-\operatorname{VECM}(p)$ has better forecasting ability than $\operatorname{VECM}(p)$. Flipping the sign gives the test statistic in the second line, where, under the null hypothesis, $\operatorname{VECM}(p)$ and $\operatorname{MSIAH}(2)-\operatorname{VECM}(p)$ have the same forecasting ability, while the alternative indicates that $\operatorname{VECM}(\mathrm{p})$ has better forecasting ability than MSIAH $(2)-\operatorname{VECM}(p)$. Small $p$-values $(<0.05$ or $<0.10)$ indicate that the forecasts on the line will be rejected in favor of the other, at $5 \%$ or $10 \%$ statistical significance level.

Overall, these results suggest that using a nonlinear MSIAH-VECM framework for the term structure of interest rates, we can generate satisfactory out-of-sample forecasts of the term structure. The gain from using a nonlinear MSIH-VECM rather than a linear VECM may be relatively small at short forecasting horizons; however, this gain generally increases with the forecast horizon and becomes very substantial indeed at the 12 months forecasting horizon, especially in case of Brazil.

\section{Discussion and Future Research Directions}

The Expectation Hypothesis of the term structure of interest rates has been at the core of macroeconomics and finance research. Several studies on the EH of term structure of interest rates 
have been conducted using various methodologies to test whether EH would hold or not (e.g., References [13-15]). Furthermore, many researchers have investigated the power of the expectations hypothesis theory of interest rates taking into account long-run deviations from equilibrium and inherent nonlinearities $[4,16]$. More recently, there are studies which have investigated the dynamic out-of-sample forecasts of the term structure to assess the effectiveness of nonlinear MS-VECM modeling (e.g., Reference [5]). Additionally to the above, BRICS countries are also in the core of the research interesting we discuss. To the best of our knowledge, there is a limited number of studies in testing the $\mathrm{EH}$ of the term structure of interest rates in BRICS countries (e.g., References $[1,20,22])$.

The aim of this paper was to identify whether the expectations hypothesis of the term structure of interest rates holds in BRICS countries and to explore the possibility of parameter instability as a crucial factor which might explain the rejection of the restricted version of the cointegration space, as well as to assess further the usefulness of nonlinear characterization of the term structure of interest rates.

Our study is different from the studies already conducted in three respects. To the best of our knowledge, none of these studies have explored the possibility of parameter instability as a crucial factor which might explain the rejection of the restricted version of the cointegration space for BRICS countries. Secondly, we extend previous studies by examining the term structure of BRICS's bond rates over a more recent time span covering the period from January 2005 to August 2019, comparing BRICS economies. Thirdly, in order to assess further the usefulness of our nonlinear MS-VECM characterization of the term structure, dynamic out-of-sample forecasts of the term structure were constructed, over a more recent time span covering the period between May 2016 and August 2019, using the MSIAH(2)-VECM(p). Performing this analysis for the recent data is important to capture the effects of the global and domestic financial crisis in BRICS economies.

The empirical findings assessed in our paper offer invaluable information for economists, central banks, and monetary policy makers, as well as contribute significantly to the existing literature. In general, the interest rate series of the majority of the short term maturities appear to move together in line with the prediction of the Expectations Hypothesis theory. More specifically, our exhaustive cointegration empirical analysis produced the following results: Firstly, for India and South Africa, the estimated VECM identified a one-to-one long-run relationship between (i) overnight and 1-month Treasury bill, (ii) the overnight and the 3-months bill, (iii) the overnight and the 6-months Treasury bill, and (vi) the overnight and the 1-year bill, whilst, for the Brazil, China, and Russia, the VECM identified a one-to-one long-run relationship between the (i) overnight and 1-month Treasury bill, (ii) the overnight and the 3-months bill, and the (iii) the overnight and the 6-months Treasury bill. Secondly, after the application of parameter stability testing we were able to show that our cointegration results are sample independent. However, the estimated coefficients exhibit some instabilities during the global financial crisis period from 2008 to 2012. Thirdly, aside from the long-run equilibrium, we revealed short-run dynamic adjustments for the term structure. Specifically, relying on advanced econometric approaches, we allowed for the underlying market linkages to be subject to regime shifts under a Markov Switching VECM framework. Thereby, we found strong evidence of nonlinearity for monthly Brazil, Russia, India, China, and South Africa interest rates. We then used Markov Switching VECM framework to forecast dynamically out of sample the term structure of interest rates, over the period May 2016 through August 2019. The forecasting results were extremely interesting. The MSIAH-VECMs' forecasts were found to be superior to the forecasts obtained from the linear VECM models, comprising the same set of variables, at a range of forecasting horizons up to 12 months ahead, using standard forecasting accuracy criteria and on the basis of standard tests of significance. Moreover, the gain from using an MSIH-VECM rather than a linear VECM generally increases with the forecast horizon and becomes very substantial indeed at the 12 months forecasting horizon, especially in case of Brazil.

The validation of the EHT for the majority of the BRICS bond yields, the possibility of parameter instability as a crucial factor which might explain the rejection of the restricted version of the cointegration space, and the usefulness of nonlinear characterization of the term structure of interest rates have many possible implications. More specifically, entrepreneurs, economists, and investors 
could make the appropriate decisions by using long-term rates, typically from government bonds, to forecast the rate for short-term bonds. Furthermore, central banks and policy makers could perform an active sovereign debt management adjusting their monetary and fiscal policies, since the maturity structure of public debt affects the government budget.

In terms of future work, there are several directions that can be pursued in order to improve upon this work. More types of nonlinear models, such as Transition Autoregressive Models (TAR) and the Smooth Transition Autoregressive Family Models (e.g., ESTAR, LSTAR, TSTAR, and GBELL-STAR), should be used as benchmarks models in order to investigate their forecastability. Additional machine learning techniques, such as neural networks or evolutionary programming algorithms (e.g., Reference [40]), could be included in order to investigate a more comprehensive evaluation of the forecasting technique for the usefulness of the of nonlinear characterization of the term structure of bond yields. Finally, the examination of the linkages between the term structure of interest rates and the macroeconomic factors is also a crucial issue for future research.

\section{Conclusions and Limitations}

In this paper, we investigated the power of the Expectation Hypothesis, taking into account cointegration effects as long-run deviations from equilibrium, regime switches, and inherent nonlinearities, utilizing monthly data of $i_{0, t}, i_{4, t}, i_{13, t}, i_{26, t}, i_{52, t}$ interest rates for Brazil, Russia, India, China, and South Africa, the so-called BRICS countries, over the period 1 January 2005 through 31 August 2019.

Overall, we provided a conclusive result with respect to the nonlinear adjustment properties of the term structure of interest rates. The shifts in mean and variance of the term structure of interest rates may be intimately related to changes in the sort of economic fundamentals one would expect to play a role in driving interest rate regimes, in particular the state of the business cycle and fluctuations in inflation. Moreover, using a MSIAH-VECM framework for the term structure of interest rates, we can generate satisfactory out-of-sample forecasts of the term structure.

As with all research studies, this work also has limitations that should be taken into account when generalizing its findings. One limitation stems from the nature of the Expectation Hypothesis Theory. A common problem with using the expectations theory is that it sometimes overestimates future short-term rates, making it easy for investors to end up with an inaccurate prediction of a bond's yield curve [41]. Another limitation of the Expectations Hypothesis theory is that many macroeconomics factors impact short- and long-term bond rates. However, long-term yields might not be as impacted because many other factors impact long-term yields including inflation and economic growth expectations. As a result, the expectations theory does not take into account the outside forces and fundamental macroeconomic factors that drive interest rates and ultimately bond yields. Finally, the limited data availability of the government interest rates for BRICS countries before 2000 is also a crucial limitation. This is a serious problem which makes extremely difficult the testing of the interest rate dynamics in a wider approach, as well, as may occur weaknesses in the forecastability of linear estimation techniques.

Author Contributions: Conceptualization, C.A. and S.B.; Data curation, C.A; Formal analysis, C.A.; Investigation, C.A. and S.B.; Methodology, C.A. and S.B.; Software, C.A.; Supervision, S.B.; Validation, C.A. and S.B.; Writing-original draft, C.A. and S.B.; Writing-review \& editing, C.A. and S.B. All authors have read and agreed to the published version of the manuscript.

Funding: This research received no external funding.

Acknowledgments: We are grateful to faculty members at the Athens University of Economics \& Business for helpful discussions. The usual disclaimers apply.

Conflicts of Interest: The authors declare no conflict of interest. 


\section{Appendix A}

\section{Brazil}
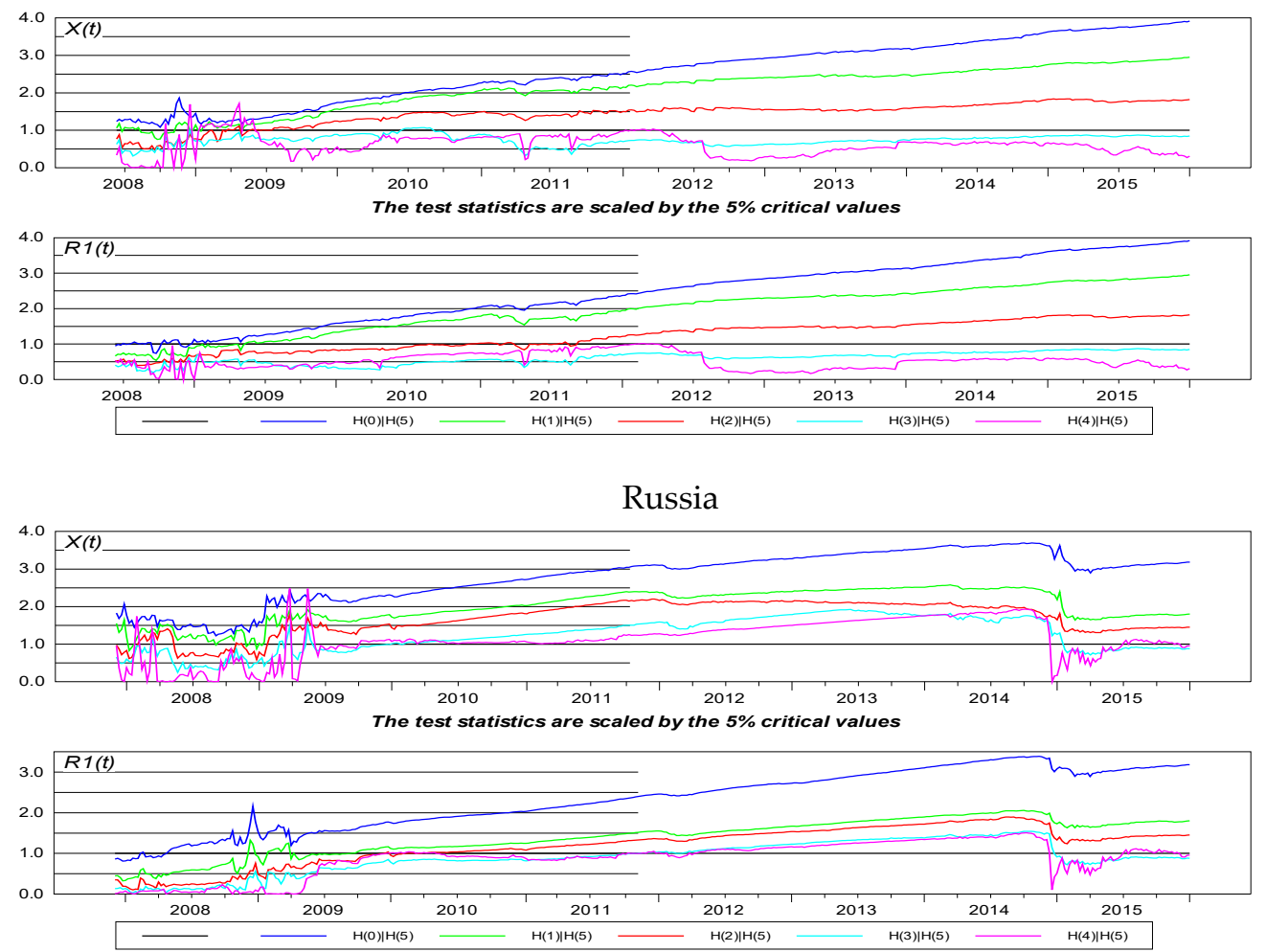

India
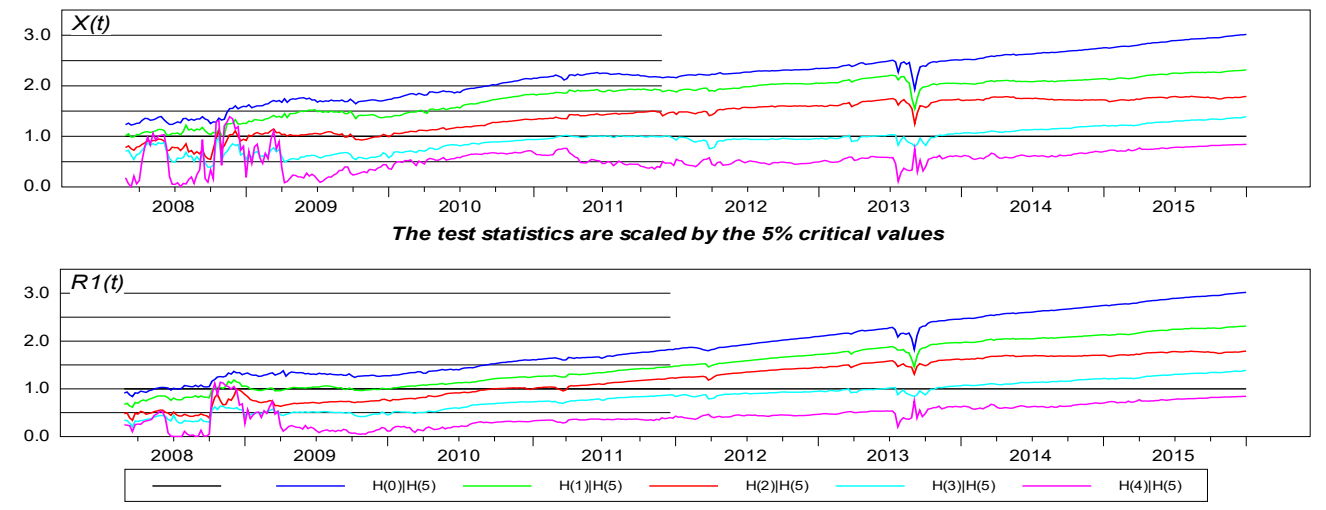

Figure A1. Trace Test Statistics. Note: "X-representation" denotes that all parameters of the cointegrated VAR system are re-estimated during the recursions, while under the "R-representation", only the long-run parameters are re-estimated. The graphs are scaled by the $5 \%$ critical value and we accept the null hypothesis that the chosen rank is maintained if it takes values greater than one, regardless of the sub-period it has been estimated for. 
China
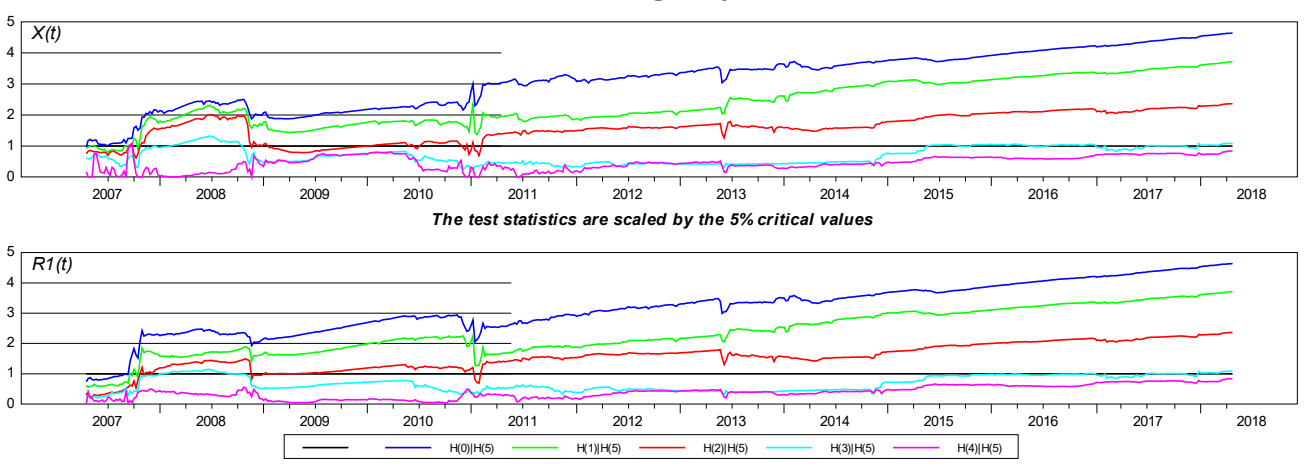

South Africa
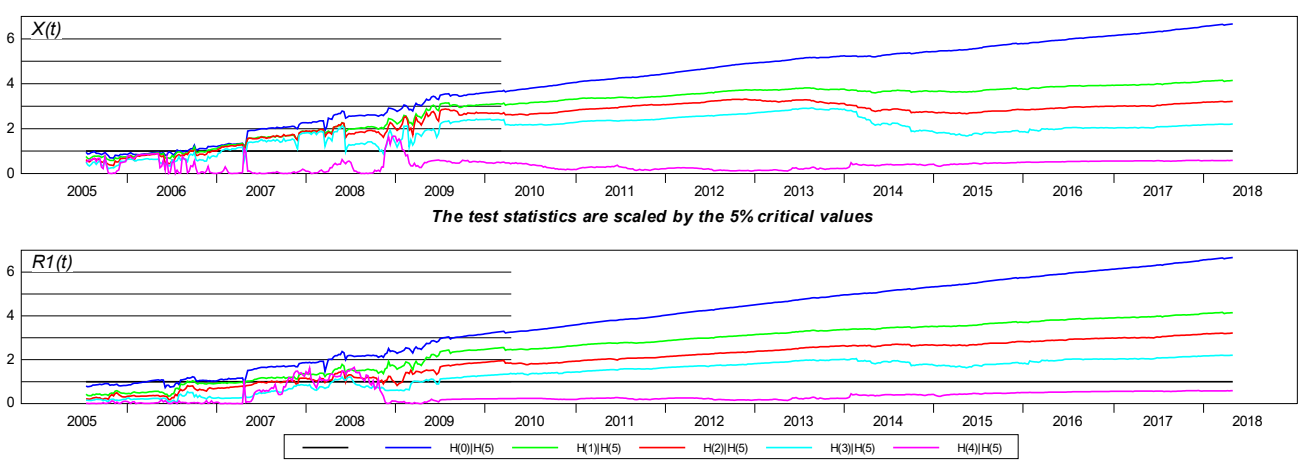

Figure A2. Trace Test Statistics. Note: "X-representation" denotes that all parameters of the cointegrated VAR system are re-estimated during the recursions, while under the "R-representation", only the long-run parameters are re-estimated. The graphs are scaled by the $5 \%$ critical value and we accept the null hypothesis that the chosen rank is maintained if it takes values greater than one, regardless of the sub-period it has been estimated for.

\section{Brazil}

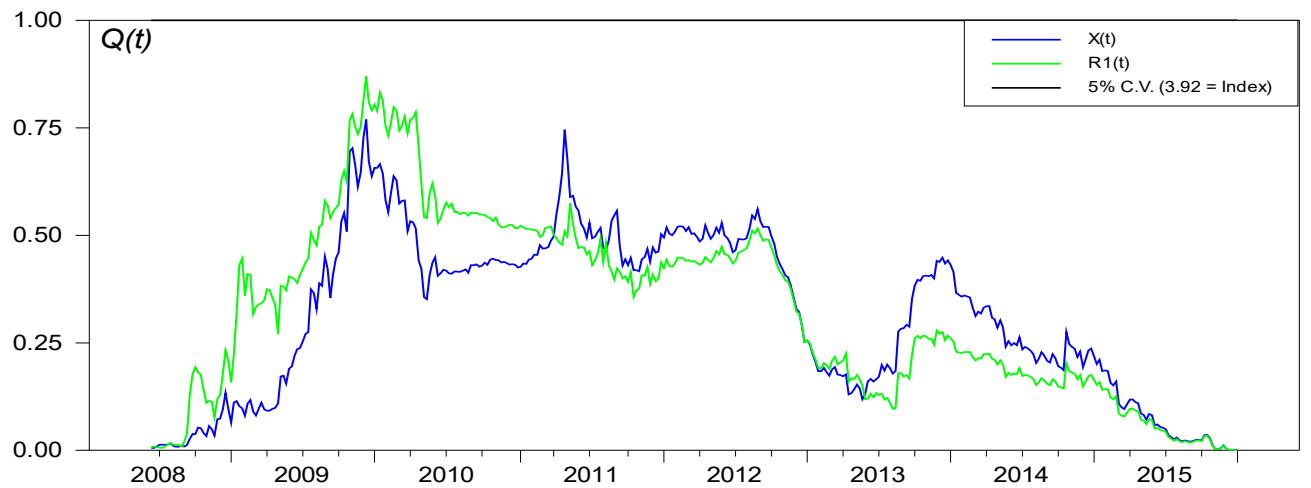

Figure A3. Cont. 
Russia

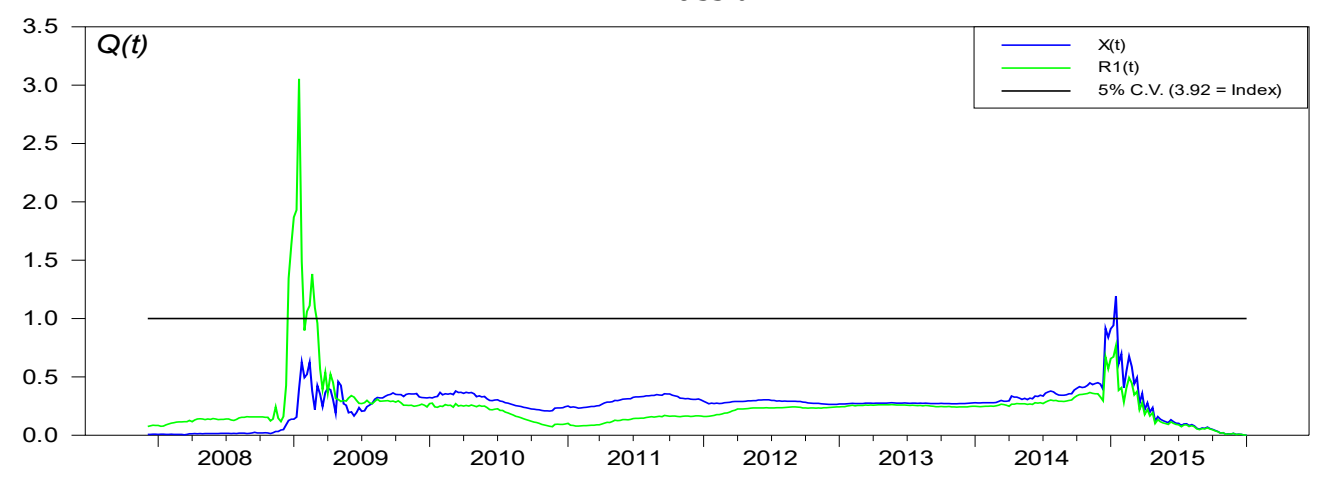

India

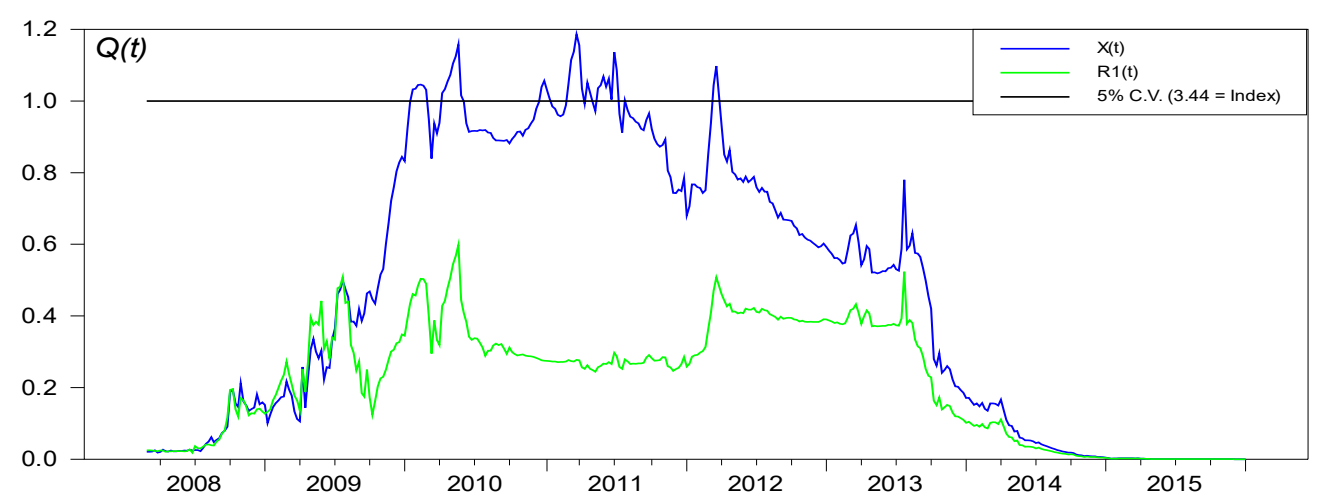

Figure A3. Recursively estimated Parameter Constancy "Known- beta Test". Note: “X-representation" denotes that all parameters of the cointegrated VAR system are re-estimated during the recursions, while under the "R-representation", only the long-run parameters are re-estimated. The graphs are scaled by the $5 \%$ critical value and therefore the null of parameter stability is rejected if the test value exceeds the value of one.

\section{China}

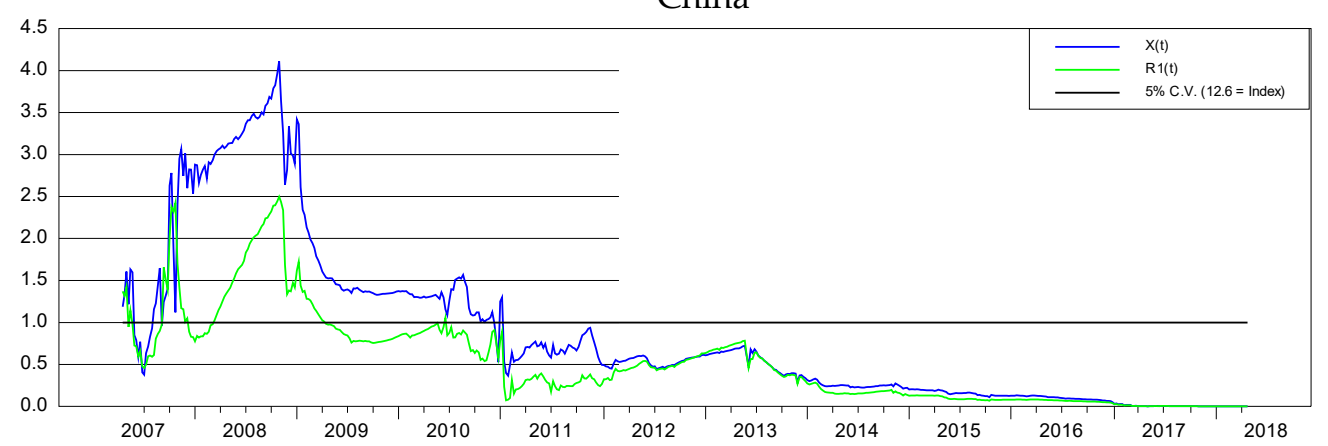

Figure A4. Cont. 
South Africa

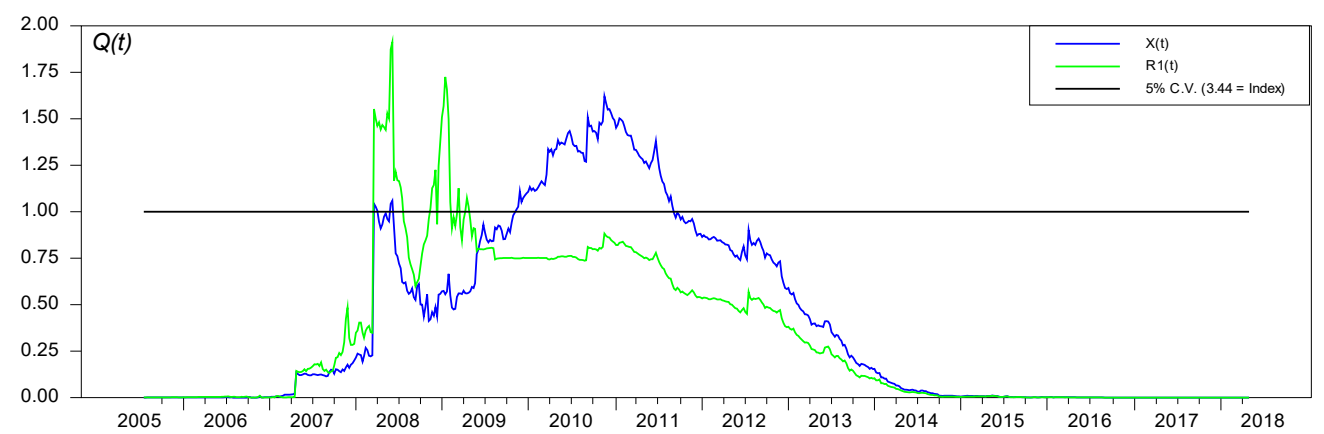

Figure A4. Recursively estimated Parameter Constancy "Known-beta Test". Note: "X-representation" denotes that all parameters of the cointegrated VAR system are re-estimated during the recursions, while under the "R-representation", only the long-run parameters are re-estimated. The graphs are scaled by the $5 \%$ critical value and therefore the null of parameter stability is rejected if the test value exceeds the value of one.
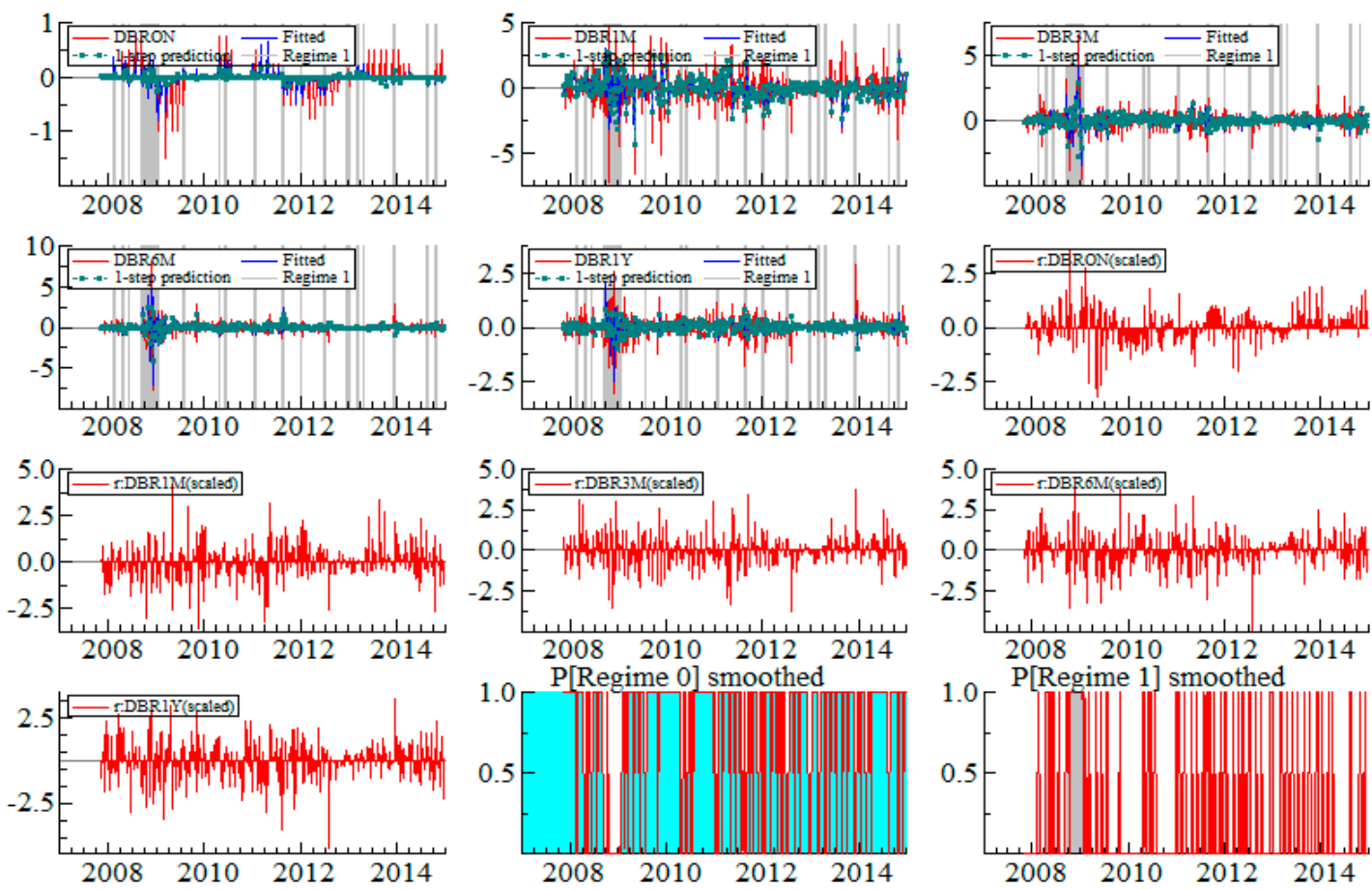

Figure A5. Brazil Regime-switching modeling: Msiah (2)-Vecm (2). Note: Regime 1 denotes the high-volatility regime, whilst Regime 0 the low-volatility one $[8,25]$. 

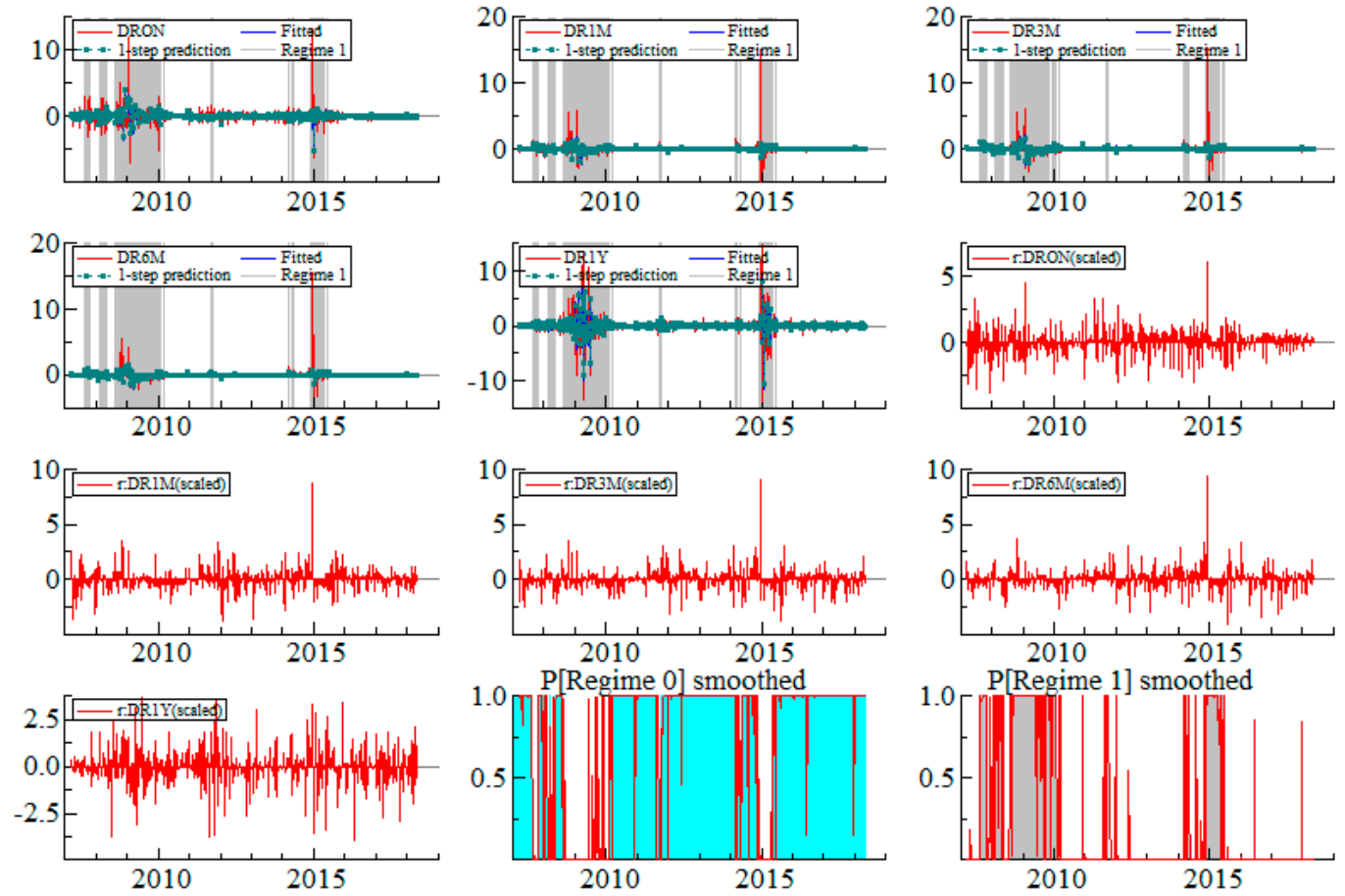

Figure A6. Russia Regime-switching modeling: Msiah (2)-Vecm (1). Note: Regime 1 denotes the high-volatility regime, whilst Regime 0 the low-volatility one [8,25].
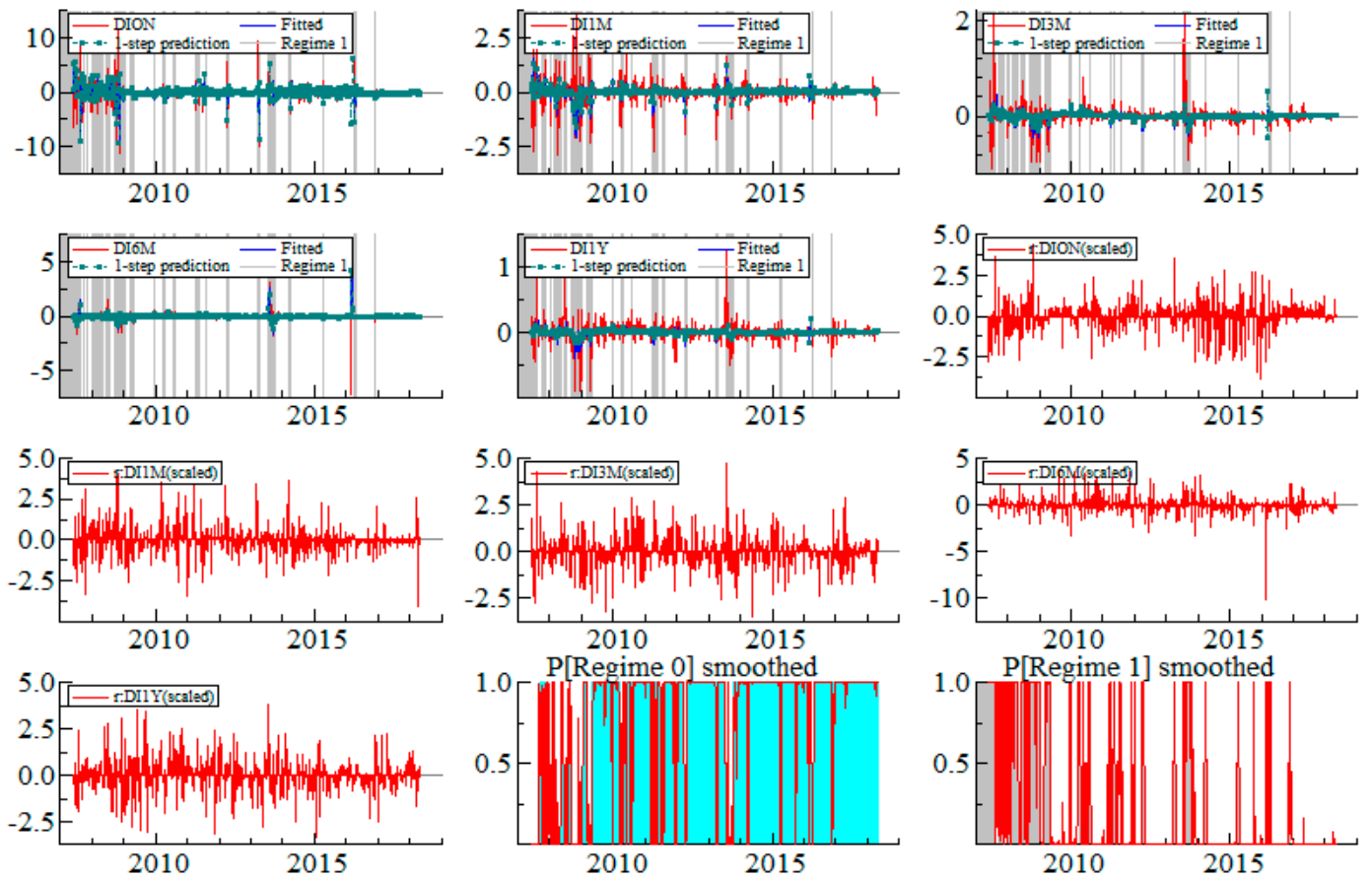

2010

2015

2015

Figure A7. India Regime-switching modeling: Msiah (2)-Vecm (1). Note: Regime 1 denotes the high-volatility regime, whilst Regime 0 the low-volatility one $[8,25]$. 

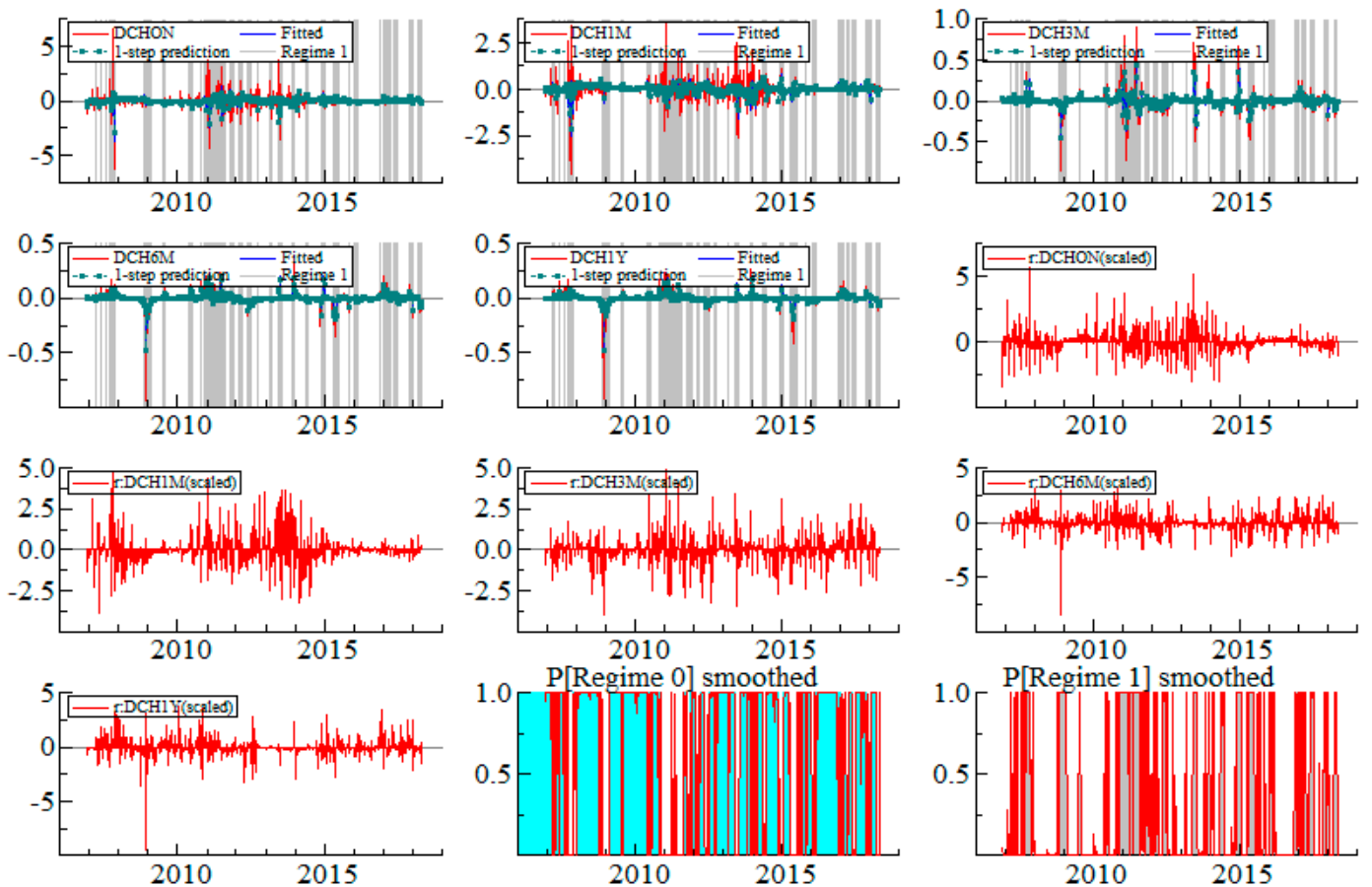

Figure A8. China Regime-switching modeling: Msiah (2)-Vecm (1). Note: Regime 1 denotes the high-volatility regime, whilst Regime 0 the low-volatility one $[8,25]$.
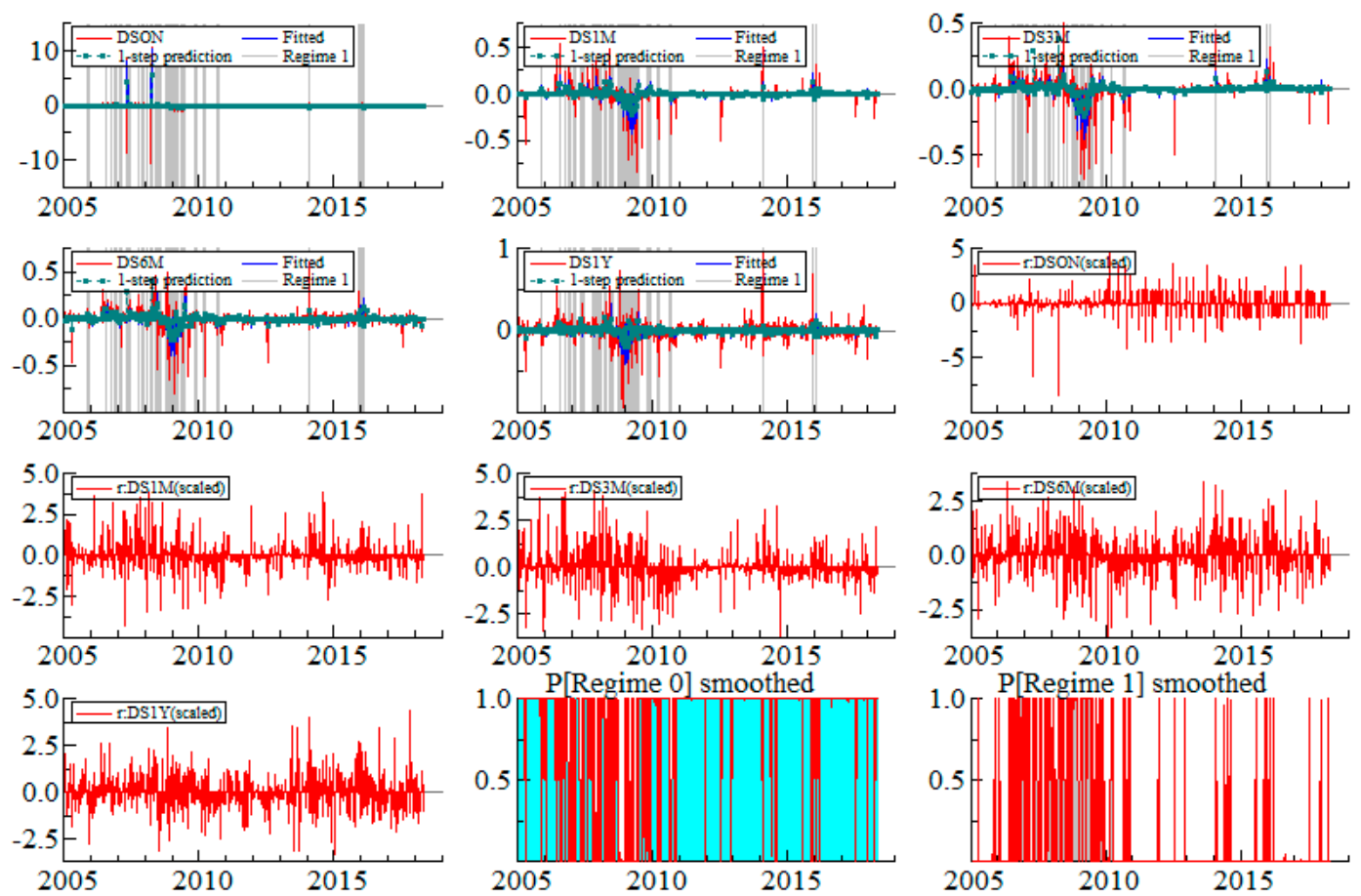

Figure A9. South Africa Regime-switching modeling: Msiah (2)-Vecm (1). Note: Regime 1 denotes the high-volatility regime, whilst Regime 0 the low-volatility one $[8,25]$. 
Appendix B

Table A1. Descriptive Statistics.

\begin{tabular}{|c|c|c|c|c|c|c|c|c|c|c|c|c|c|c|c|c|c|c|c|c|c|c|c|c|c|}
\hline & & & Brazil & & & & & Russia & & & & & India & & & & & China & & & & & outh Afri & & \\
\hline $\begin{array}{l}\text { Descriptive } \\
\text { Stats }\end{array}$ & $i_{0, t}$ & $i_{4, t}$ & $i_{13, t}$ & $i_{26, t}$ & $i_{52, t}$ & $i_{0, t}$ & $i_{4, t}$ & $i_{13, t}$ & $i_{26, t}$ & $i_{52, t}$ & $i_{0, t}$ & $i_{4, t}$ & ${ }^{i} 13, t$ & $i_{26, t}$ & $i_{52, t}$ & $i_{0, t}$ & $i_{4, t}$ & ${ }^{i} 13, t$ & $i_{26, t}$ & $i_{52, t}$ & $i_{0, t}$ & $i_{4, t}$ & $i_{13, t}$ & $i_{26, t}$ & $i_{52, t}$ \\
\hline Min & 6.400 & 2.538 & 3.055 & 3.519 & 3.930 & 1.450 & 2.730 & 3.730 & 0.000 & 4.350 & 0.25 & 3.550 & 3.100 & 0.01 & 3.500 & 0.800 & 1.013 & 1.204 & 1.465 & 1.850 & -0.001 & 4.930 & 5.063 & 5.213 & 5.350 \\
\hline Max & 19.76 & 17.11 & 17.14 & 17.67 & 15.09 & 25.00 & 29.15 & 29.92 & 30.31 & 30.00 & 50.0 & 14.62 & 11.30 & 12.00 & 10.15 & 8.528 & 9.698 & 6.389 & 5.510 & 5.255 & 11.70 & 12.20 & 12.57 & 13.14 & 13.94 \\
\hline $\begin{array}{c}\text { Mean } \\
\text { Sdd Defor }\end{array}$ & $\begin{array}{l}11.80 \\
3.156\end{array}$ & $\begin{array}{l}9.112 \\
2866\end{array}$ & $\begin{array}{l}9.044 \\
2755\end{array}$ & $\begin{array}{l}9.143 \\
2700\end{array}$ & $\begin{array}{l}9.458 \\
.574\end{array}$ & $\begin{array}{r}7.199 \\
3.348\end{array}$ & $\begin{array}{r}7.831 \\
4.032\end{array}$ & 1.997 & 8.357 & 8.939 & $\begin{array}{l}6.61 \\
258\end{array}$ & $\begin{array}{l}7.470 \\
.78\end{array}$ & 7.051 & $\begin{array}{l}7.172 \\
159\end{array}$ & 7.202 & 2.391 & $\begin{array}{l}3.620 \\
\end{array}$ & 3.763 & $\begin{array}{l}3.773 \\
.1077\end{array}$ & 3.919 & $\begin{array}{r}6.750 \\
.807\end{array}$ & $\begin{array}{l}7.066 \\
.098\end{array}$ & 7.223 & 553 & 7.937 \\
\hline $\begin{array}{l}\text { Stt. Dev. } \\
\text { Skewness }\end{array}$ & 3.156 & $\begin{array}{l}2.866 \\
-0 ? 00\end{array}$ & 2.750 & 2.708 & 2.574 & $\begin{array}{l}3.348 \\
1002\end{array}$ & 4.032 & 4.191 & $\begin{array}{l}4.405 \\
1732\end{array}$ & 3.968 & $\begin{array}{l}2.58 \\
0.54\end{array}$ & 2.584 & $\begin{array}{l}1.613 \\
-01012\end{array}$ & $\begin{array}{l}1.568 \\
\end{array}$ & 1.370 & $\begin{array}{l}0.992 \\
1.966\end{array}$ & $\begin{array}{l}1.337 \\
0.547\end{array}$ & & $\begin{array}{l}1.077 \\
-0.51\end{array}$ & 0.994 & 1.871 & 1.878 & 1.886 & 343 & 1.853 \\
\hline $\begin{array}{l}\text { Skewness } \\
\text { Kurtosis }\end{array}$ & $\begin{array}{l}0.627 \\
0.026\end{array}$ & $\begin{array}{l}-0.229 \\
-0.511\end{array}$ & $\begin{array}{l}-0.16 \\
-0.51\end{array}$ & $\begin{array}{l}-0.18 \\
-0.72\end{array}$ & $\begin{array}{l}-0.34 \\
-0.71\end{array}$ & $\begin{array}{l}1.002 \\
2.080\end{array}$ & $\begin{array}{l}1.680 \\
3.976\end{array}$ & $\begin{array}{l}1.888 \\
4.755\end{array}$ & $\begin{array}{l}1.732 \\
4.085\end{array}$ & $\begin{array}{l}2.601 \\
8485\end{array}$ & $\begin{array}{c}0.54 \\
-1.73\end{array}$ & $\begin{array}{c}0.006 \\
-1.798\end{array}$ & $\begin{array}{l}-0.122 \\
-1781\end{array}$ & $\begin{array}{l}-0.091 \\
-1.669\end{array}$ & $\begin{array}{l}-0.06 \\
-1.61\end{array}$ & $\begin{array}{l}1.961 \\
8776\end{array}$ & $\begin{array}{l}0.546 \\
11125\end{array}$ & $\begin{array}{l}-0.32 \\
-0.68\end{array}$ & $\begin{array}{l}-0.51 \\
-0.81\end{array}$ & $\begin{array}{l}-0.52 \\
-0.99\end{array}$ & $\begin{array}{c}0.106 \\
-1.305\end{array}$ & $\begin{array}{l}0.107 \\
-1.272\end{array}$ & $\begin{array}{l}0.152 \\
-1.17\end{array}$ & $\begin{array}{c}0.163 \\
-1.09\end{array}$ & $\begin{array}{l}0.162 \\
-1.03\end{array}$ \\
\hline $\begin{array}{l}\text { Kurrtosis } \\
\text { D-w }\end{array}$ & $\begin{array}{l}0.226 \\
2.013\end{array}$ & $\begin{array}{l}-0.531 \\
2.482\end{array}$ & $\begin{array}{l}-0.051 \\
2.399\end{array}$ & $\begin{array}{l}-0.727 \\
2.093\end{array}$ & $\begin{array}{l}-0.71 \\
2.472\end{array}$ & $\begin{array}{l}2.080 \\
2.305\end{array}$ & $\begin{array}{l}3.976 \\
1.943\end{array}$ & $\begin{array}{l}4.755 \\
1.914\end{array}$ & $\begin{array}{l}4.085 \\
1.864\end{array}$ & $\begin{array}{l}8.485 \\
2.415\end{array}$ & $\begin{array}{l}-1.73 \\
2.23\end{array}$ & $\begin{array}{l}-1.798 \\
2.203\end{array}$ & $\begin{array}{c}-1.781 \\
1.816\end{array}$ & $\begin{array}{l}-1.669 \\
1.952\end{array}$ & $\begin{array}{l}-1.61 \\
1.769\end{array}$ & $\begin{array}{l}8.736 \\
2.165\end{array}$ & $\begin{array}{l}1.125 \\
2.052\end{array}$ & $\begin{array}{l}-0.68 \\
1.988\end{array}$ & $\begin{array}{l}-0.81 \\
1.816\end{array}$ & $\begin{array}{l}-0.99 \\
1.859\end{array}$ & $\begin{array}{l}-1.305 \\
2.456\end{array}$ & $\begin{array}{l}-1.272 \\
1.696\end{array}$ & $\begin{array}{l}-1.17 \\
1.527\end{array}$ & $\begin{array}{l}-1.09 \\
1.684\end{array}$ & $\begin{array}{l}-1.03 \\
1.836\end{array}$ \\
\hline Jarque-Bera & 50.06 & 11.36 & 8.607 & 15.06 & 21.49 & 199.8 & 769.3 & $\begin{array}{l}1.914 \\
1046.7\end{array}$ & $\begin{array}{l}1.007 \\
736.7\end{array}$ & 2873 & 26.2 & 25.98 & $\begin{array}{l}1.010 \\
27.98\end{array}$ & 24.43 & 22.62 & 2308 & 61.98 & $\begin{array}{l}1.900 \\
22.26\end{array}$ & $\begin{array}{l}1.010 \\
42.94\end{array}$ & 53.07 & 24.03 & $\begin{array}{l}1.0070 \\
36.34\end{array}$ & $\begin{array}{l}1.027 \\
24.49\end{array}$ & $\begin{array}{l}2.1004 \\
24.16\end{array}$ & $\begin{array}{l}2.1 .500 \\
22.12\end{array}$ \\
\hline N-Test & $\begin{array}{l}93.75 \\
93.966\end{array}$ & $\begin{array}{l}172.7 \\
20.50\end{array}$ & 93.36 & $\begin{array}{l}93.18 \\
93.777\end{array}$ & $\begin{array}{l}79.38 \\
79.12\end{array}$ & $\begin{array}{l}84.99 \\
11.115\end{array}$ & 110.3 & $\begin{array}{r}50.93 \\
37 \text { 89o }\end{array}$ & $\begin{array}{l}43.27 \\
3.105\end{array}$ & $\begin{array}{l}38.80 \\
3.1540\end{array}$ & $\begin{array}{l}64.6 \\
6414\end{array}$ & $\begin{array}{l}104.5 \\
10.62\end{array}$ & $\begin{array}{l}136.4 \\
15706\end{array}$ & $\begin{array}{l}130.9 \\
03114\end{array}$ & $\begin{array}{l}65.68 \\
16908\end{array}$ & $\begin{array}{l}94.57 \\
11.46\end{array}$ & $\begin{array}{l}182.6 \\
22.60\end{array}$ & $\begin{array}{l}98.37 \\
3385\end{array}$ & $\begin{array}{l}93.29 \\
91.65\end{array}$ & 79.45 & 85.28 & $\begin{array}{l}110.3 \\
0.67\end{array}$ & $\begin{array}{l}51.00 \\
37798\end{array}$ & $\begin{array}{l}42.84 \\
\text { T2.57 }\end{array}$ & 39.21 \\
\hline $\begin{array}{l}\text { H-Test } \\
\text { ARCH }\end{array}$ & 13.966 & 20.650 & 32.844 & 21.777 & 29.112 & 12.115 & 21.670 & 37.888 & 21.605 & 21.540 & 1.414 & 40.563 & 45.796 & 21.416 & 16.938 & 14.466 & 22.660 & 33.854 & 21.605 & 29.005 & 12.476 & 21.670 & 37.798 & 21.575 & 21.4 \\
\hline $\begin{array}{c}\text { ARCH } \\
\text { Test }\end{array}$ & 4.111 & 13.111 & 12.201 & 11.001 & 7.233 & 3.998 & 13.271 & 12.381 & 10.503 & 7.121 & 9.785 & 6.313 & 4.190 & 4.962 & 3.472 & 4.134 & 13.271 & 12.381 & 10.503 & 7.121 & 4.445 & 12.998 & 12.477 & 9.990 & 8.967 \\
\hline
\end{tabular}

Notes. Ithes testing first-order autocorrelation. $N$-Test denotes the

Normality test by Dornik \& Hansen, while the $H$-Test is the Heteroscedasticity test of White. The ARCH-Test is the Autoregressive Conditional Heteroscedasticity by Engle. The diagnostics were produced using the reduced-form residuals. 
Table A2. Unit Root testing.

\begin{tabular}{|c|c|c|c|c|c|c|c|c|c|c|c|c|c|c|c|}
\hline \multirow[t]{3}{*}{ Maturity } & \multicolumn{3}{|c|}{ Brazil } & \multicolumn{3}{|c|}{ Russia } & \multicolumn{3}{|c|}{ India } & \multicolumn{3}{|c|}{ China } & \multicolumn{3}{|c|}{ South Africa } \\
\hline & & & & & & & \multicolumn{3}{|c|}{ Levels } & & & & & & \\
\hline & ADF & PP & ERS & ADF & PP & ERS & ADF & PP & ERS & ADF & PP & ERS & ADF & PP & ERS \\
\hline$i_{0, t}$ & -3.285 & -1.257 & -3.630 & -2.026 & -1.960 & -1.418 & -2.635 & -2.529 & -2.426 & -2.529 & -2.551 & -2.414 & -1.266 & -1.311 & -1.118 \\
\hline$i_{4, t}$ & -1.393 & -4.334 & -1.733 & -2.716 & -2.655 & -1.453 & -2.624 & -1.967 & -2.555 & -2.502 & -2.563 & -2.488 & -1.749 & -1.389 & -1.651 \\
\hline$i_{13, t}$ & -1.556 & -2.060 & -1.345 & -2.779 & -2.727 & -1.384 & -1.798 & -1.912 & -1.797 & -2.369 & -2.187 & -2.352 & -1.754 & -1.310 & -1.612 \\
\hline$i_{26, t}$ & -1.411 & -2.272 & -1.583 & -2.754 & -2.638 & -1.387 & -1.991 & -1.987 & -1.996 & -2.533 & -1.929 & -2.522 & -1.917 & -1.298 & -1.772 \\
\hline$i_{52, t}$ & -1.200 & -1.454 & -1.432 & -2.645 & -2.640 & -1.354 & -2.060 & -1.924 & -2.064 & -2.462 & -1.862 & -2.451 & -1.835 & -1.410 & -1.698 \\
\hline & & & & \multicolumn{6}{|c|}{ 1st Differences } & & & & & & \\
\hline$\Delta i_{0, t}$ & -3.098 & -27.810 & -3.120 & -7.727 & -6.006 & -3.178 & -11.10 & -11.10 & -10.99 & -9.870 & -41.896 & -9.190 & -6.54 & -6.110 & -3.007 \\
\hline$\Delta i_{4, t}$ & -9.611 & -45.255 & -5.494 & -6.136 & -6.112 & -3.136 & -7.492 & -7.492 & -7.486 & -8.756 & -31.082 & -8.757 & -6.12 & -6.003 & -3.212 \\
\hline$\Delta i_{13, t}$ & -8.705 & -33.799 & -6.231 & -6.036 & -6.038 & -3.129 & -7.233 & -7.233 & -7.164 & -5.790 & -14.044 & -5.797 & -6.14 & -5.998 & -3.066 \\
\hline$\Delta i_{26, t}$ & -6.959 & -46.783 & -5.747 & -5.728 & -5.732 & -3.008 & -7.720 & -7.720 & -7.274 & -4.921 & -13.985 & -4.922 & -5.25 & -5.811 & -2.993 \\
\hline$\Delta i_{52, t}$ & -7.078 & -32.248 & -4.826 & -6.425 & -6.399 & -3.027 & -6.203 & -6.203 & -6.030 & -4.859 & -14.652 & -4.857 & -6.38 & -6.276 & -3.001 \\
\hline
\end{tabular}

Notes: The results comprise the Augmented Dickey-Fuller, Phillips-Perron, and Elliot, Rothenberg, and Stock test statistics for the null of a unit-root process; the symbols $i_{0, t}, i_{4, t}, i_{13, t}, i_{26, t}$,

$i_{52, t}$ represent the overnight, one-month, three-month, six-month, and one-year Eurorates, respectively and $\Delta$ is the first-difference operator. The critical values at $1 \%$ ( $5 \%$ ) significance level for ADF is -3.446 (-2.867) (MacKinnon [32]) for a maximum lag- length of 12 for each country; for the PP test it is -3.46 ( $(-2.87)$ while for the ERS it is -3.28 (-2.23). Italics types, bold types denote no unit root at $10 \%$ and $5 \%$ significance level, respectively. 
Table A3. Johansen trace statistics.

\begin{tabular}{|c|c|c|c|c|c|c|c|}
\hline$p-r$ & $r$ & Eigenvalue & Trace & Trace* & Frac95 & $p$-Value & $p$-Value ${ }^{*}$ \\
\hline \multicolumn{8}{|c|}{ Brazil } \\
\hline$p-r$ & $r$ & Eigenvalue & Trace & Trace* & Frac95 & $p$-value & $p$-value \\
\hline 5 & 0 & 0.266 & 272.75 & 267.499 & 69.611 & 0 & 0 \\
\hline 4 & 1 & 0.184 & 140.926 & 138.661 & 47.707 & 0 & 0 \\
\hline 3 & 2 & 0.092 & 54.361 & 53.463 & 29.804 & 0 & 0 \\
\hline 2 & 3 & 0.028 & 13.104 & 12.507 & 15.408 & 0.111 & 0.135 \\
\hline 1 & 4 & 0.003 & 1.199 & 1.078 & 3.841 & 0.273 & 0.299 \\
\hline \multicolumn{8}{|c|}{ Russia } \\
\hline$p-r$ & $r$ & Eigenvalue & Trace & Trace* & Frac95 & $p$-value & $p$-value \\
\hline 5 & 0 & 0.254 & 221.657 & 221.657 & 69.611 & 0 & 0 \\
\hline 4 & 1 & 0.088 & 86.058 & 86.058 & 47.707 & 0 & 0 \\
\hline 3 & 2 & 0.062 & 43.344 & 43.344 & 29.804 & 0.001 & 0.001 \\
\hline 2 & 3 & 0.021 & 13.537 & 13.537 & 15.408 & 0.096 & 0.096 \\
\hline 1 & 4 & 0.008 & 3.684 & 3.684 & 3.841 & 0.055 & 0.055 \\
\hline \multicolumn{8}{|c|}{ India } \\
\hline$p-r$ & $r$ & Eigenvalue & Trace & Trace* & Frac95 & $p$-value & $p$-value \\
\hline 5 & 0 & 0.198 & 210.137 & 210.137 & 69.611 & 0 & 0 \\
\hline 4 & 1 & 0.119 & 110.528 & 110.528 & 47.707 & 0 & 0 \\
\hline 3 & 2 & 0.068 & 53.356 & 53.356 & 29.804 & 0 & 0 \\
\hline 2 & 3 & 0.039 & 21.395 & 21.395 & 15.408 & 0.005 & 0.005 \\
\hline 1 & 4 & 0.007 & 3.236 & 3.236 & 3.841 & 0.072 & 0.072 \\
\hline \multicolumn{8}{|c|}{ China } \\
\hline$p-r$ & $r$ & Eigenvalue & Trace & Trace* & Frac95 & $p$-value & $p$-value ${ }^{*}$ \\
\hline 5 & 0 & 0.108 & 130.117 & 130.117 & 69.611 & 0 & 0 \\
\hline 4 & 1 & 0.083 & 75.803 & 75.803 & 47.707 & 0 & 0 \\
\hline 3 & 2 & 0.042 & 34.389 & 34.389 & 29.804 & 0.013 & 0.013 \\
\hline 2 & 3 & 0.02 & 14.123 & 14.123 & 15.408 & 0.079 & 0.079 \\
\hline 1 & 4 & 0.009 & 4.538 & 4.538 & 3.841 & 0.09 & 0.09 \\
\hline \multicolumn{8}{|c|}{ South Africa } \\
\hline$p-r$ & $r$ & Eigenvalue & Trace & Trace ${ }^{*}$ & Frac95 & $p$-value & $p$-value ${ }^{*}$ \\
\hline 5 & 0 & 0.485 & 711.716 & 709.264 & 69.61 & 0 & 0 \\
\hline 4 & 1 & 0.199 & 250.462 & 249.79 & 47.707 & 0 & 0 \\
\hline 3 & 2 & 0.081 & 96.568 & 96.382 & 29.804 & 0 & 0 \\
\hline 2 & 3 & 0.05 & 37.733 & 37.689 & 15.408 & 0 & 0 \\
\hline 1 & 4 & 0.003 & 2.291 & 2.29 & 3.841 & 0.13 & 0.13 \\
\hline
\end{tabular}

Notes: $p-r$ is the number of unit roots, $r$ is the number of the cointegrating vectors, the Eigenvalue depicts the estimated eigenvalues, and Trace symbolizes the trace test statistic. The Trace* is the small sample corrected trace test statistic at the $95 \%$ significance level. The Frac95 represents the 5\% critical value for the test of $H(r)$ against $H(r-1)$, and the $p$-value the approximate $p$-value using the uncorrected test statistic with $\Gamma$-distribution; the $p$-value* is the approximate score using the corrected test statistic.

\section{References}

1. Beechey, M.; Hjalmarsson, E.; Österholm, P. Testing the expectations hypothesis when interest rates are near integrated. Ssrn Electron. J. 2008, 33, 934-943.

2. Shanming, Q. Financial Integration within the BRICS. CRI English. Available online: http://english.cri.cn/ 7146/2013/04/10/3381s758725.htm (accessed on 2 July 2015).

3. Juselius, K. The Cointegrated VAR Approach: Methodology and Applications. In Textbook on the Econometrics of the Cointegrated Vector Autoregression Model; Economics Institute, University of Copenhagen: Copenhagen, Denmark, 2004.

4. Clarida, R.; Sarno, L.; Taylor, M.P.; Valente, G. The Role of Asymmetries and Regime Shifts in the Term Structure of Interest Rates. J. Bus. 2006, 79, 1193-1224. [CrossRef]

5. Bekiros, S.; Avdoulas, C.; Hassapis, C. Nonlinear Equilibrium Adjustment Dynamics and Predictability of the Term Structure of Interest Rates. Int. Rev. Financ. Anal. 2018, 55, 140-155. [CrossRef] 
6. Hansen, H.; Johansen, S. Recursive Estimation in Cointegrated VAR-Models; Institute of Mathematical Statistics Working Paper 1; University of Copenhagen: Copenhagen, Denmark, 1993.

7. Hansen, H.; Johansen, S. Some tests for parameter constancy in co-integrated VAR models. Econom. J. 1999, 2, 306-333. [CrossRef]

8. Krolzig, H.M. Markov Switching Vector Autoregressions. Modelling Statistical Inference and Application to Business Cycle Analysis; Springer: Berlin/Heidelberg, Germany, 1997.

9. Fisher, I. Appreciation and Interests. Publ. Am. Econ. Assoc. 1896, 11, 21-29.

10. Fama, E.F.; Bliss, R.R. The Information in Long-Maturity Forward Rates. Am. Econ. Rev. 1987, 77, 680-692.

11. Campbell, J.; Shiller, R. Yield Spreads and Interest Rate Movements: A Bird's Eye View. Rev. Econ. Stud. 1991, 58, 495-514. [CrossRef]

12. Shiller, R.J. Alternative tests of rational expectations models: The case of the term structure. J. Econom. 1981, 16, 71-87. [CrossRef]

13. Campbell, J.Y.; Clarida, R.H. The term structure of euromarket interest rates: An empirical investigation. J. Monet. Econ. 1986, 19, 25-44. [CrossRef]

14. Campbell, J.Y.; Shiller, R.J. Cointegration and tests of present value models. J. Political Econ. 1987, 95, 1062-1088. [CrossRef]

15. Hall, A.D.; Anderson, H.M.; Granger, C.W.J. A cointegration analysis of Treasury bill yields. Rev. Econ. Stat. 1992, 74, 116-126. [CrossRef]

16. Johansen, S.; Juselius, K. Testing Structural Hypotheses in a Multivariate Cointegration Analysis of the PPP and UIP for U.K. J. Econom. 1992, 53, 211-244. [CrossRef]

17. Johansen, S. Likelihood-Based Inference in Cointegrated Vector Auto-Regressive Models; Oxford University Press: Oxford, UK, 1996.

18. Juselius, K.; MacDonald, R. International Parity Relationships between Germany and the United States: A Joint Modelling Approach; University of Copenhagen, Institute of Economics: Copenhagen, Denmark, 2000.

19. Hamilton, J.D. A new approach to the economic analysis of nonstationary time series and the business cycle. Econometrica 1989, 57, 357-384. [CrossRef]

20. Shelile, T. The Term Structure of Interest Rates and Economic Activity in South Africa. MCom Thesis, Rhodes University, Grahamstown, South Africa, 2006.

21. Shivam, M.; Jayadev, M. The Interest Rate Term Structure in the Indian Money Market. In Proceedings of the VIth Annual Conference on Money and Finance, Mumbai, Indian, 25-27 March 2004.

22. Shareef, H.; Shijin, S. Expectations Hypothesis and Term Structure of Interest Rates: An Evidence from Emerging Market. Asia-Pac. Financ. Mark. 2016, 23, 137-152. [CrossRef]

23. Hendry, D.F.; Juselius, K. Explaining cointegration analysis: Part, I. Energy J. 2000, 21, 1-42. [CrossRef]

24. Hendry, D.F.; Juselius, K. Explaining cointegration analysis: Part II. Energy J. 2001, 22, 75-120. [CrossRef]

25. Krolzig, H. Regime-Switching Models; Department of Economics and Nuffield College, University of Oxford: Oxford, UK, 2002.

26. Sarno, L.; Valente, G. Modeling and Forecasting Stock Returns: Exploiting the Futures Market, Regime Shifts and International Spillovers. J. Appl. Econom. 2005, 20, 345-376. [CrossRef]

27. Sarno, L.; Valente, G. Deviations from purchasing power parity under different exchange rate regimes: Do they revert and, if so, how? J. Bank. Financ. 2006, 30, 3147-3169. [CrossRef]

28. Johansen, S. Estimation and Hypothesis Testing of Cointegration Vectors in Gaussian Vector Autoregressive Models. Econometrica 1991, 59, 1551-1580. [CrossRef]

29. Diebold, F.X.; Mariano, R.S. Comparing predictive accuracy. J. Bus. Econ. Stat. 1995, 13, $253-265$.

30. Bai, J.; Perron, P. Computation and Analysis of Multiple Structural Change Models. J. Appl. Econom. 2003, 18, 1-22. [CrossRef]

31. Dickey, D.; Fuller, W. Likelihood Ratio Statistics for Autoregressive Time Series with a Unit Root. Econometrica 1981, 49, 1057-1072. [CrossRef]

32. MacKinnon, J.G. Critical Values for Cointegration Tests. In Long-Run Economic Relationships: Readings in Cointegration; Engle, R.F., Granger, C.W.J., Eds.; Oxford University Press: Oxford, UK, 1991.

33. Said, S.E.; Dickey, D.A. Testing for unit roots in autoregressive moving average models of unknown order. Biometrika 1984, 71, 599-607. [CrossRef]

34. Phillips, P.C.B.; Perron, P. Testing for a Unit Root in Time Series Regression. Biometrika 1988, 75, 335-346. [CrossRef] 
35. Elliot, B.E.; Rothenberg, T.J.; Stock, J.H. Efficient Tests of the Unit Root Hypothesis. Econometrica 1996, 64, 813-836. [CrossRef]

36. Ljung, G.M.; Box, G.E.P. On a Measure of a Lack of Fit in Time Series Models. Biometrika 1978, 65, $297-303$. [CrossRef]

37. Johansen, S.; Juselius, K. Maximum Likelihood and Inferences on Cointegration: With Applications to the Demand for Money. Oxf. Bull. Econ. Stat. 1990, 52, 169-210. [CrossRef]

38. Johansen, S. A Barlett correction factor for tests on the cointegration relations. Econom. Theory 2000, 16, 740-778. [CrossRef]

39. Johansen, S. A small sample correction of the test for cointegration rank in the vector of autoregressive model. Econometrica 2002, 70, 1929-1961. [CrossRef]

40. Avdoulas, C.; Bekiros, S.; Boubaker, S. Evolutionary-based return forecasting with nonlinear STAR models: Evidence from the Eurozone peripheral stock markets. Ann. Oper. Res. 2018, 262, 307-333. [CrossRef]

41. Cieslak, A. Short-Rate Expectations and Unexpected Returns in Treasury Bonds. Rev. Financ. Stud. 2018, 31, 3265-3306. [CrossRef]

(C) 2020 by the authors. Licensee MDPI, Basel, Switzerland. This article is an open access article distributed under the terms and conditions of the Creative Commons Attribution (CC BY) license (http://creativecommons.org/licenses/by/4.0/). 